\title{
A Facially Coordinating Tris-Benzimidazole Ligand for Nonheme Iron Enzyme Models: Biomimetic or Radical Aerobic Oxidation?
}

\author{
Parami S. Gunasekera, ${ }^{\dagger}$ Preshit C. Abhyankar, ${ }^{\dagger}$ Samantha N. MacMillan, ${ }^{\S}$ David C. Lacy* ${ }^{* \dagger}$ \\ 'Department of Chemistry, University at Buffalo, State University of New York, Buffalo, New York 14260, United States. \\ $\S$ Department of Chemistry and Chemical Biology, Cornell University, Ithaca, New York 14853, United States.
}

Supporting Information Placeholder

\begin{abstract}
Herein, we report a rationally designed tripodal tris-benzimidazole ligand (Tbim) that structurally mimics the 3 -His coordination environment of certain nonheme mono-nuclear iron oxygenases. The coordination chemistry of Tbim was explored with iron(II) and the ability of the iron complexes to oxidize biomimetic model substrates lithium diethyl 2-phenylmalonate and sodium thiocresolate was studied.
\end{abstract}

Molecular oxygen $\left(\mathrm{O}_{2}\right)$ is the most sustainable oxidant in oxidative transformation. It is no surprise then that the design of new catalysts take inspiration from (di)oxygenases, which are enzymes that incorporate O-atoms from $\mathrm{O}_{2}$ into a substrate. Many of these enzymes are irondependent and contain a two-histidine one-carboxylate (2-His-1-C) facial triad binding pocket. ${ }^{1,2}$ Recently, additional binding modes have been discovered, and these include the three-histidine (3-His), three-histidine one-carboxylate, and four histidine binding modes. ${ }^{3}$

Modelling the 3-His coordination has been attempted through various nitrogen donor ligands such as 1,4,7triazacyclononane $(\operatorname{tacn}),{ }^{4} \quad$ tris(2-pyridyl)methane (Tpym) ${ }^{5}$ trispyrazolyl variants namely trispyrazolylborates $(\mathbf{T p}){ }^{6}{ }^{6}$ trispyrazolylmethanes $(\mathbf{T p m})^{7}$ and trisimidazolylphosphines (TIP), ${ }^{8}$ and other ligands., ${ }^{9,10}$ Some of these facially coordinating ligands have been used to prepare Fe-based $\mathrm{O}_{2}$ derived oxidants, such as superoxo and oxo species, ${ }^{11-16}$ and there are a few catalytic examples..$^{17,18}$

In our pursuit to prepare structurally faithful 3-His mononuclear nonheme iron model complexes, we noted that despite similar coordination geometry, most of the ligands contain donor groups that are not representative of those in nature (Figure 1). For instance, histidine donors are imidazole nitrogen groups with $\mathrm{sp}^{2}$ hybridization and in an aromatic ring. In contrast, tacn has $\mathrm{sp}^{3}$ hybridization and is not conjugated. Accordingly, we noted that Gebbink and coworkers modeled the 2-His-1-C facial triad using imidazole and benzimidazole ligands

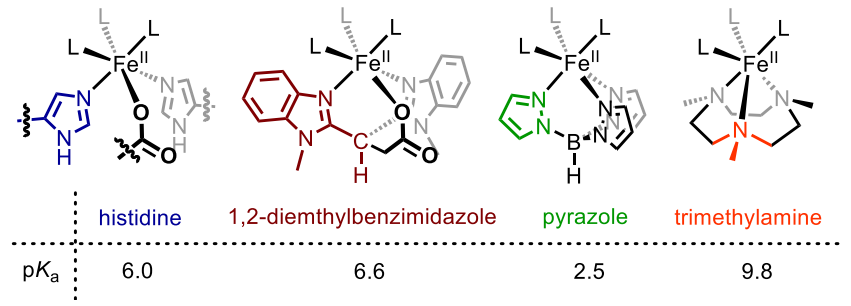

Figure 1. Natural two-histidine one-carboxylate enzyme binding site (left) compared to tridentate ligands with representative "mono-dentate" ligand donor groups and their respective $[\mathrm{NH}]^{+}$ $\mathrm{p} K_{\mathrm{a}}$ in water (see Fig. S19 and Table $\mathrm{S} 1$ for more examples).

(2bim1C) with surprising structural precision and also functional chemistry. ${ }^{19,20}$ In addition to the electronic similarity (i.e. $\mathrm{sp}^{2}$ hybridized and aromatized) with the donor groups in Gebbink's 2bim1C and histidine, benzimidazole and imidazole have excellent $\mathrm{p} K_{\mathrm{a}}$ similarities to histidine. For instance, the $\mathrm{p} K_{\mathrm{a}}$ of the nitrogen donor of histidine is 6.0 in water, ${ }^{21}$ which is close to the $\mathrm{p} K_{\mathrm{a}}$ of 6.6 for 1,2-dimethylbenzimidazole that is the donor moiety in Gebbink's 2bim1C ligand. ${ }^{22,23}$ Ligands with similar coordination modes and electronic properties are thought to impart the appropriate thermodynamic requirements for functional chemistry. ${ }^{24}$ Therefore, inspired by Gebbink's 2bim1C ligand, we report herein the synthesis of a novel 3-His model with a tris-benzimidazole ligand, 2,2'-(2-(1ethylbenzimidazol-2yl)ethane-1,1-diyl)bis(1-methylbenzimidazole) (Tbim), its coordination with iron and a brief foray into catalysis.

Synthesis. Our synthesis of the new ligand Tbim used a strategy similar to the one Gebbink used to prepare 2bim1C (Scheme 1). ${ }^{20,25,26}$ With ligand in hand, we explored the coordination chemistry of Tbim using a variety of $\mathrm{FeX}_{2}$ salts $(\mathrm{X}=\mathrm{OAc}, \mathrm{Cl}, \mathrm{OTf})$. Inspired from certain successful work with $\mathbf{T p}$ * to afford mono-ligated complexes, ${ }^{11}$ we performed an analogous reaction with Tbim and $\mathrm{Fe}(\mathrm{OAc})_{2}$ in a dichloromethane/acetonitrile solvent mixture (Scheme 2). Crystals suitable for diffraction revealed the mono-ligated complex $\left[\mathrm{Fe}\{\mathbf{T b i m}\}(\mathrm{OAc})_{2}\right]$ (1) (Figure 2). Both acetates are $\kappa-2$ and Tbim is bound through the two benzimidazole arms 
Scheme 1. Ligand Synthesis

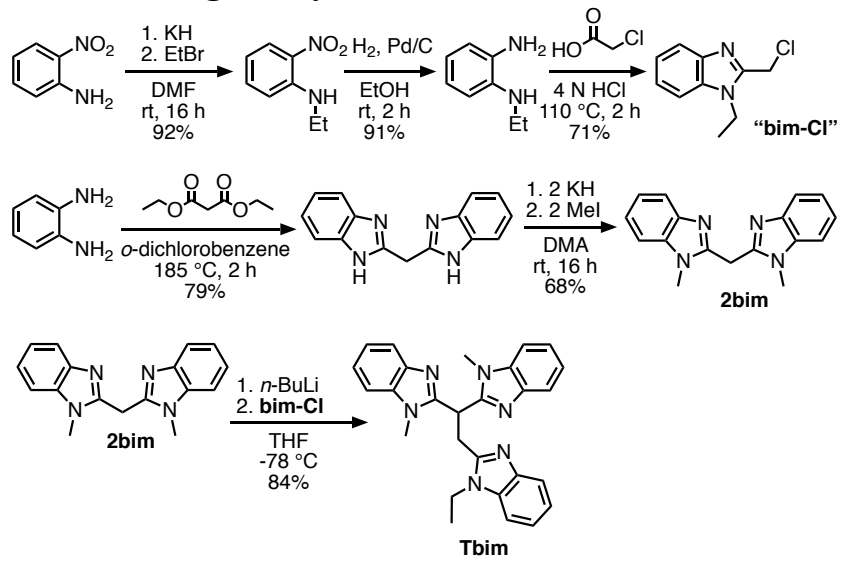

Scheme 2. Synthesis of 1 and 2

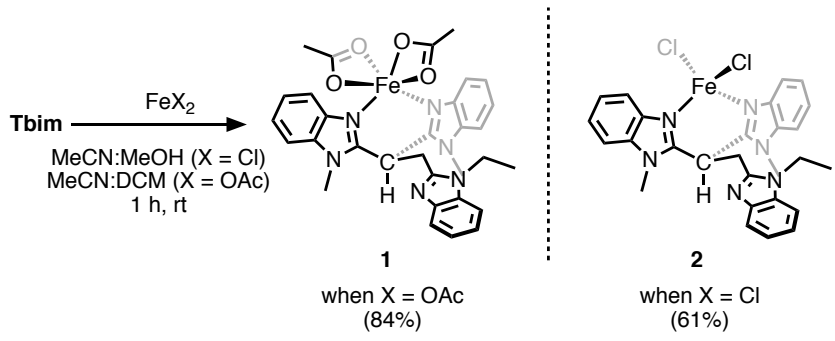

that form six-membered chelate rings. The third benzimidazole arm, if bound to the metal, would give a sevenmembered ring that is apparently unfavored over acetate $\kappa-2$ coordination. The complex shows paramagnetically shifted ${ }^{1} \mathrm{H}$ NMR signals in the range -20 ppm to $90 \mathrm{ppm}$; Evans method was conducted and is consistent with an $\mathrm{S}$ $=2$ ground state for $1\left(\mu_{\mathrm{eff}}=5.31\right)$. ATR-FTIR characterization shows $\mathrm{C}-\mathrm{O}$ stretches from the acetate groups at 1605 and $1564 \mathrm{~cm}^{-1}$. Tbim also reacts with $\mathrm{FeCl}_{2}$ to produce the complex $\left[\mathrm{Fe}\{\mathbf{T b i m}\}(\mathrm{Cl})_{2}\right]$ (2) that is structurally similar to 1 (Figure 2).

Salt metatheses were performed on $\mathbf{1}$ and $\mathbf{2}$ in an attempt to remove a single acetato or chlorido ligand and coordinate the third benzimidazole arm to iron. For instance, we attempted the reaction of 1 with $\mathrm{NaBPh}_{4}$ in methanol. The reaction produced a yellow precipitate from which we obtained colourless crystals of the formulation $\left[\mathrm{Fe}\{\mathbf{T b i m}\}_{2}\right]\left[\mathrm{BPh}_{4}\right]_{2}\left([3]\left[\mathrm{BPh}_{4}\right]_{2}\right)$, which is a bisligated metal complex salt whose connectivity was confirmed through XRD (Figure S16).

A reaction of Tbim with $\mathrm{Fe}(\mathrm{OTf})_{2} \cdot 2 \mathrm{MeCN}$ in acetonitrile also produced the bis-ligated metal complex [3][OTf $]_{2}$. However, if a different workup procedure was used for the same in situ prepared 1:1 ligand:metal mixture, a different product was obtained. Namely, if the acetonitrile reaction mixture was removed in vacuo to near dryness and the resulting residue dissolved in dichloromethane the mono-ligated metal complex $\left[\mathrm{Fe}\{\right.$ Tbim $\left.\}(\mathrm{MeCN})_{2}(\mathrm{OTf})\right][\mathrm{OTf}] \quad([4][\mathrm{OTf}])$ was obtained in moderate yields. The presence of acetonitrile ligands is confirmed from ATR-FTIR spectroscopy $\left(v_{\mathrm{CN}}\right.$ $=2279$ and $2285 \mathrm{~cm}^{-1}$ ) and X-ray crystallography
Scheme 3. Synthesis of $[3]^{2+}$ and $[4]^{+}$



[3] ${ }^{2+}$ $(56 \%)$
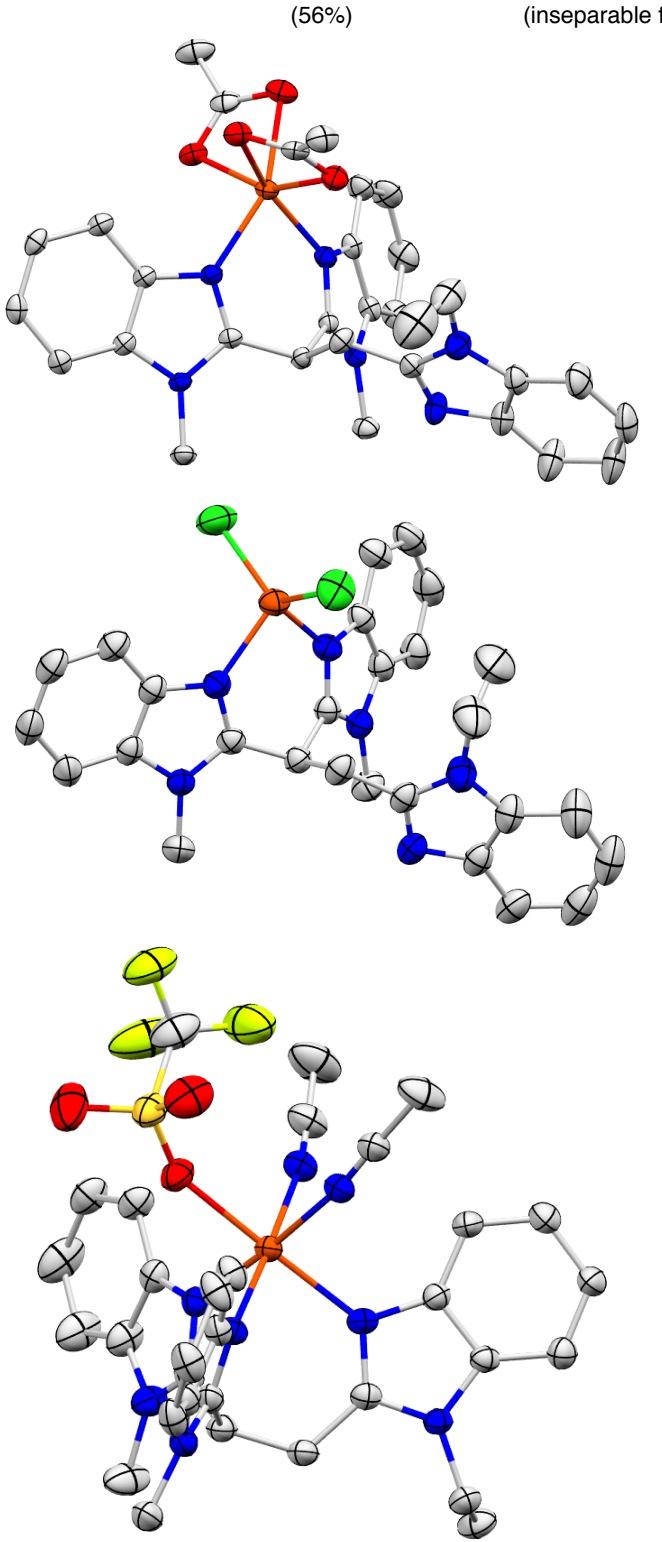

Figure 2. Molecular structure of (top to bottom) 1,2 and [4] $]^{+}$ with ellipsoids shown at $50 \%$ probability; $\mathrm{H}$-atoms, counterions, and solvent molecules are not shown. Color scheme: orange $=\mathrm{Fe}$; blue $=\mathrm{N}$; red $=\mathrm{O}$; yellow $/$ green $=\mathrm{F} ;$ yellow $=\mathrm{S}$; green $=\mathrm{Cl}$; grey $=\mathrm{C}$.

(Figure 2). Nevertheless, [4][OTf] was inseparable from $[3][\mathrm{OTf}]_{2}$ under the conditions studied here.

Titration of Tbim with $\mathrm{Fe}(\mathrm{OTf})_{2} \cdot 2 \mathrm{MeCN}$ in acetonitrile followed by ${ }^{1} \mathrm{H}$ NMR and ${ }^{19} \mathrm{~F}\left\{{ }^{1} \mathrm{H}\right\}$ NMR provided insight into the coordination behaviour of Tbim in 
solution. The ${ }^{1} \mathrm{H}$ NMR data indicates the presence of both the mono-ligated and the bis-ligated complex in acetonitrile in a 1:1 reaction mixture (Figure $\mathrm{S} 15)$. The ${ }^{19} \mathrm{~F}\left\{{ }^{1} \mathrm{H}\right\}$ NMR spectrum of a 2:1 ligand:metal ratio contains a single, sharp peak at $-80 \mathrm{ppm}$ consistent with an unbound triflate ion for $[3][\mathrm{OTF}]_{2}{ }^{20}$ In contrast, when the ratio is less than 2:1, a broad signal is apparent at $-73 \mathrm{ppm}$ indicative of an equilibrium between bound and unbound triflate ions in solution implicating the presence of monoligated species $[4]^{+}$(Figure S12). This is consistent with a Schlenk equilibrium between $[3]^{2+}$ and $[4]^{+}$at room temperature in $\mathrm{MeCN}$; using density functional theory (DFT), the calculated equilibrium lies toward the bis ligated complex with a free energy of $-3.2 \mathrm{kcal} / \mathrm{mol}$ (see SI). ${ }^{1} \mathrm{H}$ NMR spectroscopy was used to construct a kind of "Job plot" to determine the optimal ratio of $\mathrm{Fe}(\mathrm{OTf})_{2}$ :Tbim to prepare in situ $[4]^{+}$for the catalysis studies later (Figure $\mathrm{S} 17$ ), and a $\mathrm{Fe}(\mathrm{OTf})_{2}$ :Tbim stoichiometry of $3: 2$ was the optimal ratio to achieve the highest concentration of $[4]^{+}$in the $10 \mathrm{mM}$ regime.

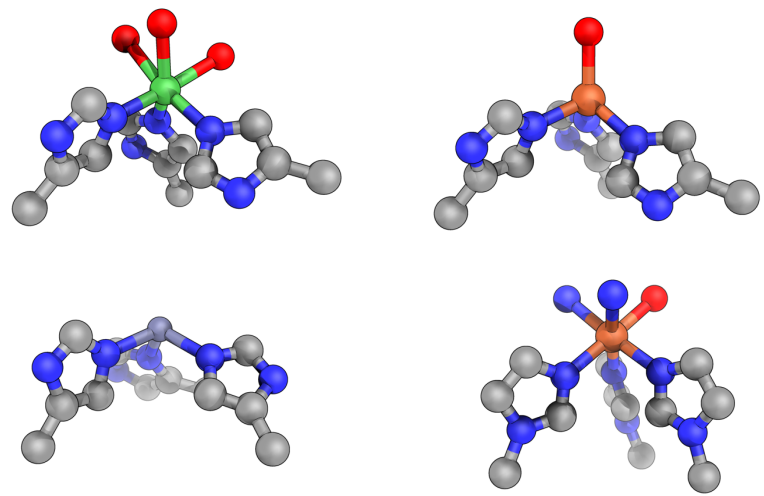

Figure 3. Simplified primary coordination spheres of three-histidine iron enzymes and $[4]^{+}$. Clockwise from top left: PDB 2atf, ${ }^{27}$ PDB $2 \mathrm{~b} 5 \mathrm{~h},{ }^{28}[4]^{+}, \mathrm{PDB} 3 \mathrm{bal} .{ }^{29}$ Color scheme: grey $=\mathrm{C}$; blue $=\mathrm{N}$; red $=\mathrm{O}$; orange $=\mathrm{Fe}$; green $=\mathrm{Ni}$; blue-grey $=\mathrm{Zn}$.

Structural Comparison to Enzymes. In mononuclear $\mathrm{Fe}(\mathrm{II})$ three-histidine enzymes, the protein derived facial triad nominally occupies the face of a pseudo octahedron. Likewise, Tbim occupies the same face and thereby provide a biomimetic binding mode (Figure 3). However, there are some notable differences. The average benzimidazole $\mathrm{Fe}-\mathrm{N}$ distance of $[4]^{+}$is $2.15 \AA$ (average distance for all $\mathrm{Fe}-\mathrm{N} / \mathrm{O}$ bonds in $[4]^{+}$is $2.16 \AA$ ), whereas the average $\mathrm{Fe}-\mathrm{N} / \mathrm{O}$ distance in resting state mammalian cysteine dioxygenase (CDO) determined through K-edge EXAFS is $2.04 \AA .{ }^{30}$ Additionally, the protein structures' $\mathrm{N}-\mathrm{M}-\mathrm{N}$ angles are about $100^{\circ}$ (average angle $95.7^{\circ}$ for 2atf, $100.6^{\circ}$ for $2 \mathrm{~b} 5 \mathrm{~h}$, and $102.4^{\circ}$ for $3 \mathrm{bal}$ ), whereas $[4]^{+}$has an average $\mathrm{N}-\mathrm{Fe}-\mathrm{N}$ angle of $89.9^{\circ}$ for the benzimidazole nitrogen atoms. Also, it is to be noted that, unlike the binding mode in Tbim and other synthetic ligands (e.g., Tp), the protein active site imidazoles twist into a paddle wheel conformation.

Catalysis. The ability of the Tbim system to perform catalytic oxidation was tested using the substrate lithium diethyl 2-phenylmalonate (Li[Phmal]) in accordance with following Limberg's reported biomimetic catalyst (Scheme 4). ${ }^{17}[\mathrm{Phmal}]^{-}$anion is often used as a model substrate instead of acetylacetonate (acac) because acac, ${ }^{17,31}$ which is a natural substrate for acetylacetone dioxygenase (Dke1), is difficult to oxidize and sluggish even in nature $\left(k_{\mathrm{cat}}=6.5 \mathrm{~s}^{-1}\right) .{ }^{32}$ The expected biomimetic product ethyl benzoylformate was independently synthesized and characterized using ${ }^{1} \mathrm{H}$ NMR, ${ }^{13} \mathrm{C}$ NMR, and GC-MS (Figure S20-S22). As a positive control, we attempted to reproduce Limberg's catalytic oxidation of Li[Phmal] wherein they successfully isolated ethyl benzoylformate as the sole product with a TOF of $55 \mathrm{~h}^{-1}$ (TON not reported). ${ }^{17}$ Unfortunately, our efforts to reproduce this chemistry using $[\mathbf{T p} * \mathrm{Fe}(\mathrm{Phmal})]$ have failed. Specifically, we obtained diethyl 2-hydroxy-2-phenylmalonate (HOPhmal) as the major product following the literature method (Table 1). ${ }^{17}$

\section{Scheme 4. Catalytic 1,3-Diester Oxidation Studies}

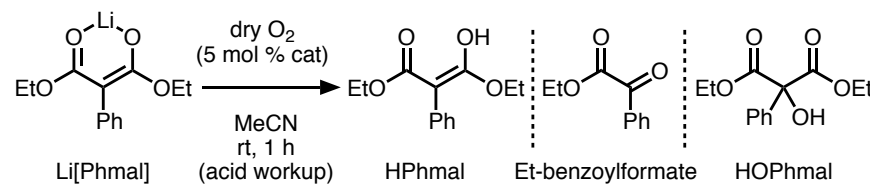

(a)

(b)

(c)

Table 1. Results from catalytic aerobic oxidation of lithium diethyl 2-phenylmalonate ( $\mathrm{Li}[\mathrm{Phmal}]) .{ }^{[\mathrm{a}]}$

\begin{tabular}{|c|c|c|c|}
\hline $\mathrm{cat}^{[\mathrm{b}]}$ & a (\%) & b $(\%)$ & $\mathrm{c}(\%)$ \\
\hline Fe/Tbim (3:2); “[4] $]^{+} "$ & 0 & 22 & 41 \\
\hline Fe/Tbim (1:4); “[3] $]^{2+”}$ & 0 & 17 & 51 \\
\hline$\left[\left\{\mathbf{T} \mathbf{p}^{*}\right\} \mathrm{Fe}(\mathrm{Phmal})\right]$ & 0 & 21 & 45 \\
\hline $\mathbf{F e}$ & 0 & 16 & 41 \\
\hline $\mathbf{F e}+\mathrm{Ph}_{2} \mathrm{NH}$ & 61 & 0 & 17 \\
\hline no iron or ligand & 77 & 0 & 4 \\
\hline
\end{tabular}

[a] Conditions: Substrate added dropwise, $5 \mathrm{~mol} \%$ catalyst, dry $\mathrm{O}_{2}, 1 \mathrm{~h}$; data reported average of two runs, see SI for full data. [b] $\mathbf{F e}=\mathrm{Fe}(\mathrm{OTf})_{2} \cdot 2 \mathrm{MeCN} ; \mathbf{F e} / \mathbf{L}$ represents that complex was prepared in situ. If water is not rigorously excluded, HOPhmal (a) is the sole product.

Nearly identical results were obtained when [Phmal] oxidations were repeated using $[4]^{+},[3]^{2+}$, and $\mathrm{Fe}(\mathrm{OTf})_{2}$ (Table 1). In the absence of catalyst, or if water was not rigorously excluded, the HPhmal or HOPhmal was obtained as the major product. These results are actually consistent with another literature report that used electrochemically generated superoxide to oxidize the same lithiated substrate to form ethyl benzoylformate and 2-hydroxy-2-phenylmalonate. ${ }^{33}$ Given that the control reaction with iron triflate gives nearly identical results, we conclude that the observed oxidized products arise from superoxide generation by an iron(II) species followed by simple radical-chain oxidation. This is also consistent with Comba's assertion that radical pathways are likely 
the general case. ${ }^{34}$ We performed a control oxidation with iron triflate and five equiv. diphenylamine, the oxygen radical scavenger, and found that HPhmal was obtained as the major product accompanied by a small amount of HOPhmal. This is strikingly different from the results obtained with iron triflate in the absence of the radical scavenger further indicating that the observed chemistry with all four iron complexes (i.e., $[4]^{+},[3]^{2+}$, $[\{\mathbf{T p} *\} \mathrm{Fe}(\mathrm{Phmal})]$, and $\left.\mathrm{Fe}(\mathrm{OTf})_{2}\right)$ is similar to the known system that relies on electrochemically generated free superoxide. $^{3334}$

Scheme 5. Catalytic Thiolate Oxidation Studies

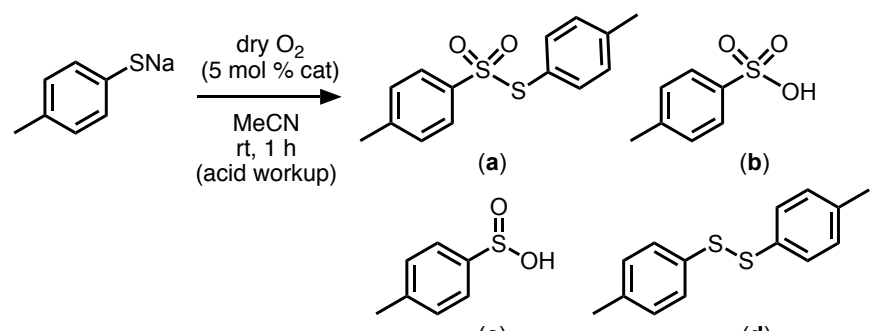

(c)

(d)

Table 2. Results from catalytic aerobic oxidation of thiocresolate. ${ }^{[a]}$

\begin{tabular}{|c|c|c|c|c|}
\hline $\mathrm{cat}^{[\mathrm{b}]}$ & $\mathbf{a}(\%)$ & $\mathbf{b}(\%)$ & $\mathbf{c}(\%)$ & $\mathbf{d}(\%)$ \\
\hline $\mathbf{F e} / \mathbf{T b i m}(3: 2) ; "[4]^{+"}$ & 16 & 0 & 54 & 29 \\
\hline Fe/Tbim (1:4); " $[\mathbf{3}]^{2+}$, & 5 & 10 & 66 & 18 \\
\hline $\mathrm{Fe} / \mathrm{Tp} *$ & 9 & 2 & 70 & 19 \\
\hline $\mathrm{Fe}$ & 15 & 5 & 61 & 19 \\
\hline $\begin{array}{l}\text { no iron or ligand } \\
\text { (w/o Na } \mathrm{NaDTA}_{2} \text { ) }\end{array}$ & 4 & 19 & 71 & 5 \\
\hline $\begin{array}{l}\text { no iron or ligand } \\
\left.\text { (w/ } \mathrm{Na}_{2} \mathrm{EDTA}\right)\end{array}$ & 1 & 6 & 87 & 6 \\
\hline
\end{tabular}

[a] Conditions: $5 \mathrm{~mol} \%$ catalyst, dry $\mathrm{O}_{2}, 1 \mathrm{~h}$; data presented average of two runs, see SI for full data. [b] $\mathbf{F e}=$ $\mathrm{Fe}(\mathrm{OTf})_{2} \cdot 2 \mathrm{MeCN} ; \mathbf{F e} / \mathbf{L}$ represents that complex was prepared in situ.

Another common substrate used in 3-His biomimetic studies is thiophenolate as a mimic for $\mathrm{CDO}$, which oxidizes aliphatic thiols to sulfinic acids. For instance, the 3His model ligand Tpym was used to model enzyme function by selective oxidation of sodium thiophenolate to phenylsulfinyl acid..$^{5}$ In our study, we chose to use sodium thiocresolate because the products are easily examined using ${ }^{1} \mathrm{H}$ NMR spectroscopy; the use of NMR spectroscopy alleviates certain issues that arise from product

1. Bruijnincx, P. C. A.; Van Koten, G.; Gebbink, R. J. M. K. Mononuclear Non-Heme Iron Enzymes with the 2-His-1-Carboxylate Facial Triad: Recent Developments in Enzymology and Modeling Studies. Chem. Soc. Rev. 2008, 37, 2716-2744.

2. Koehntop, K. D.; Emerson, J. P.; Que, L. The 2-His-1-Carboxylate Facial Triad: A Versatile Platform for Dioxygen instability ${ }^{35}$ and limitations associated with chromatographic analysis of highly acidic thiophenol oxidation products. Oxidation of thiocresol in $\mathrm{MeCN}$ using in situ $[4]^{+},[3]^{2+}, \mathrm{Fe} \mathbf{T} \mathbf{p}^{*}$, and $\mathrm{Fe}(\mathrm{OTf})_{2}$ resulted in similar complicated ranges of products (Scheme 5, Table 2). It has been noted that trace metal impurities- and/or base-catalyzed thiol oxidations can give a variety of products including sulfinic acid. ${ }^{36,37}$

In conclusion, we have synthesized a ligand and coordination complexes with iron that structurally mimics the 3-His active site in nonheme iron enzymes. We also attempted to demonstrate catalytic oxidation chemistry using the substrates LiPhmal and sodium thiocresolate and the results indicate radical-based oxidations. The radical nature of these oxidations, rather than biomimeticlike function, is generally consistent with critical evaluations from others, ${ }^{34}$ known literature reactivity of these substrates, ${ }^{33,36,37}$ and industrial aerobic oxidation chemistry. ${ }^{38}$ While these substrates are often used in biomimetic studies mimicking Dke1 and CDO, our results demonstrate that they are inadequate to conclusively elucidate functional biomimicry. Therefore, future studies using more robust substrates and solvents should be undertaken, and the inclusion of control experiments is paramount. The importance of judiciously chosen control reactions, which are often absent in biomimetic model studies claiming catalytic function, cannot be understated. The lesson here emphasizes the difficulty in producing a bona fide biomimetic synthetic nonheme (di)oxygenase where the enzymes incorporate $\mathrm{O}$-atoms from $\mathrm{O}_{2}$ into substrate through $\mathrm{Fe}$-based $\mathrm{O}_{2}$-dervied oxidants.

\section{ASSOCIATED CONTENT}

\section{Supporting Information.}

The Supporting Information is available free of charge.

\section{AUTHOR INFORMATION}

\section{Corresponding Author}

DCLacy@Buffalo.edu

\section{ACKNOWLEDGMENT}

Financial support was provided by the University at Buffalo (UB). This work was completed using the resources of the Chemistry Instrument Center (CIC) and Center for Computational Research (CCR) at UB.

\section{REFERENCES}

Activation by Mononuclear Non-Heme Iron(II) Enzymes. J. Biol. Inorg. Chem. 2005, 10, 87-93.

3. Buongiorno, D.; Straganz, G. D. Structure and Function of Atypically Coordinated Enzymatic Mononuclear Non-HemeFe(II) Centers. Coord. Chem. Rev. 2013, 257, 541-563. 
4. Blakesley, D. W.; Payne, S. C.; Hagen, K. S. Spin-State Variation in Solid State and Solution of Mononuclear Iron (II). Inorg. Chem. 2000, 39, 1979-1989.

5. Anandababu, K.; Ramasubramanian, R.; Wadepohl, H.; Comba, P.; Britto, N. J.; Jaccob, M.; Mayilmurugan, R. A structural and functional model for the tris-histidine motif in cysteine dioxygenase. Chem. Eur. J. 2019, 25, 9540-9547.

6. Sallmann, M.; Limberg, C. Utilizing the Trispyrazolyl Borate Ligand for the Mimicking of 02-Activating Mononuclear Nonheme Iron Enzymes. Acc. Chem. Res. 2015, 48, 27342743.

7. Reger, D. L.; Little, C. A.; Rheingold, A. L.; Sommer, R.; Long, G. J. Synthesis, Solid-State Structure, Magnetic Properties and Mössbauer Spectral Studies of $\{\mathrm{Fe}[\mathrm{HC}(3,5-$ Me2Pz)3](H2O)3\}(BF4)2. Inorganica Chim. Acta, 2001, 316, 65-70.

8. Tazelaar, C. G. J.; Slootweg, J. C.; Lammertsma, K. Coordination chemistry of tris (azolyl) phosphines. Coord. Chem. Rev. 2018, 356, 115-126.

9. Sahu, S.; Goldberg, D. P. Activation of Dioxygen by Iron and Manganese Complexes: A Heme and Nonheme Perspective. J. Am. Chem. Soc. 2016, 138, 11410-11428.

10. Que, L.; Tolman, W. B. Biologically Inspired Oxidation Catalysis. Nature 2008, 455, 333-340.

11. Oddon, F.; Chiba, Y.; Nakazawa, J.; Ohta, T.; Ogura, T.; Hikichi, S. Characterization of Mononuclear Non-heme Iron(III)Superoxo Complex with a Five-Azole Ligand Set. Angew. Chem., Int. Ed., 2015, 54, 7336-7339.

12. Fischer, A. A.; Lindeman S. V.; Fiedler, A. T. A synthetic model of the nonheme iron-superoxo intermediate of cysteine dioxygenase Chem. Commun. 2018, 54, 11344.

13. Gordon, J. B.; Vilbert, A. C.; DiMucci, I. M.; MacMillan, S. N.; Lancaster, K. M.; Moëmme-Loccoz, P.; Goldberg, D. P. Activation of dioxygen by a mononuclear nonheme iron complex: Sequential peroxo, oxo, and hydroxo intermediates. J. Am. Chem. Soc. 2019, 141, 17533-17547.

14. Kass, D.; Corona, T.; Warm, K.; Braun-cula, B.; Kuhlmann, U.; Bill, E.; Mebs, S.; Swart, M.; Dau, H.; Haumann, M.; Hildebrandt, P.; Ray, K. Stoichiometric Formation of an Oxoiron(IV) Complex by a Soluble Methane Monooxygenase Type Activation of 02 at an Iron(II)- Cyclam Center.J. Am. Chem. Soc. 2020, 142, 5924-5928.

15. Chiang, C.W.; Kleepspies, S. T.; Stout, H. D; Meier, K. K.; Li, P.Y.; Bominaar, E. L.; Que, L.; Münk, E.; Lee, W.Z. Characterization of a paramagnetic mononuclear nonheme iron-superoxo complex. J. Am. Chem. Soc. 2014, 136, 10846.

16. Blakely, M. N.; Dedushko, M. A.; Poon, P. C. Y.; Villar-Acevedo, G.; Kovacs, J. A. Formation of a reactive, alkyl thiolate-ligated FelII-superoxo intermediate derived from dioxygen. J. Am. Chem. Soc. 2019, 141, 1867-1870.

17. Siewert, I.; Limberg, C. A. Trispyrazolylborato iron malonato complex as a functional model for the acetylacetone dioxygenase. Angew. Chem. Int. Ed., 2008, 47, 7953-7956.

18. Debobrata, S.; Paine, T. K. Aerobic Alcohol Oxidation and Oxygen Atom Transfer Reactions Catalyzed by a Nonheme Iron(II)- Alpha-Keto Acid Complex. Chem. Sci. 2016, 7, 53225331.

19. Bruijnincx, P. C. A.; Lutz, M.; Spek, A. L.; Hagen, W. R.; Weckhuysen, B. M.; Van Koten, G.; Gebbink, R. J. M. K. Modeling the 2-His-1-Carboxylate Facial Triad: Iron-Catecholato Complexes as Structural and Functional Models of the Extradiol Cleaving Dioxygenases. J. Am. Chem. Soc. 2007, 129, 2275-2286.

20. Bruijnincx, P. C. A.; Lutz, M.; Spek, A. L.; Van Faassen, E. E.; Weckhuysen, B. M.; Van Koten, G.; Klein Gebbink, R. J. M. Bis(1Methylimidazol-2-Yl)Propionates and Bis(1Methylbenzimidazol-2-Yl)- Propionates: A New Family of Biomimetic N,N,O Ligands - Synthesis, Structures and CuII
Coordination Complexes. Eur. J. Inorg. Chem. 2005, 4, 779787.

21. Moser, A.; Range, K.; York, D. M. Accurate Proton Affinity and Gas-Phase Basicity Values for Molecules Important in Biocatalysis. J. Phys. Chem. B. 2010, 114, 13911-13921.

22. The $\mathrm{pKa}$ of 1,2-dimethylbenzimidazole was measured as part of this work (see SI).

23. Martínez, C. H. R.; Dardonville, C. Spectroscopy Using 96-Well Microtiter Plates. ACS Med. Chem. Lett. 2013, 4, 142-145.

24. Lacy, D. C. Applications of the Marcus Cross Relation to Inner Sphere $\mathrm{O}_{2}$ Reduction: Implications in Small Molecule Activation. Inorg. Chem. Front. 2019, 6, 2396-2403.

25. Elgafi, S.; Field, L. D.; Messerle, B. A.; Turner, P.; Hambley, T. W. Rhodium Complexes Containing Bidentate Imidazolyl Ligands: Synthesis and Structure. J. Organomet. Chem. 1999, 588, 69-77.

26. Sahay, I. I.; Ghalsasi, P. S. Synthesis of New 1,2,3-Triazole Linked Benzimidazole Molecules as Anti-Proliferative Agents. Synth. Commun. 2017, 47, 825-834.

26. J. G. McCoy, L. J. Bailey, E. Bitto, C. A. Bingman, D. J. Aceti, B. G. Fox, G. N. Phillips, Structure and mechanism of mouse cysteine dioxygenase. Proc. Natl. Acad. Sci. U.S.A. 2006, 103, 30843089.

28. C. R. Simmons, Q. Huang, Q Hao, T. P. Begley, P. A. Karplus, M. H. Stipanuk. Crystal structure of mammalian cysteine dioxygenase. A novel mononuclear iron center for cysteine thiol oxidation. J. Biol. Chem. 2006, 281, 18723-18733.

29. G. R. Stranzl, U. G. Wagner, G. Straganz, W. Steiner and C. Kratky, Protein Data Bank in Europe, https://www.ebi.ac.uk/pdbe/entry/pdb/3bal, (accessed June 2020), unpublished work.

30. Chai, S. C.; Bruyere, J. R.; Maroney, M. J. Probes of the Catalytic Site of Cysteine Dioxygenase. J. Biol. Chem. 2006, 281, 1577415779.

31. (a) Allpress, C. J.; Grubel, K.; Szajna-Fuller, E.; Arif, A. M.; Berreau, L. M. Regioselective aliphatic carbon-carbon bond cleavage by a model system of relevance to iron-containing acireductone dioxygenase. J. Am. Chem. Soc. 2013, 135, 659668. (b) Park, H.; Bittner, M. M.; Baus, J. S.; Lindeman, S. V.; Fiedler, A. T. Fe(II) complexes that mimic the active site structure of acetylacetone dioxygenase: 02 and NO reactivity. Inorg. Chem. 2013, 135, 659-668. (c) Park, H.; Baus, J. S.; Lindeman, S. V.; Fiedler, A. T. Synthesis and characterization of $\mathrm{Fe}(\mathrm{II}) \quad \beta$-diketonato complexes with relevance to acetylacetone dioxygenase: insights into the electronic properties of the 3-histidine facial triad. Inorg. Chem. 2011, 50, 11978-11989. (d) Ramasubramanian, R.; Anandababu, K.; Kumar, M.; Mayilmurugan, R. Nickel(II) complexes of a $3 \mathrm{~N}$ ligand as a model for diketon cleaving unusual nickel(II)dioxygenase enzymes. Dalton Tran. 2018, 47, 4049-4053.

32. Straganz, G. D.; Nidetzky, B. Reaction coordinate analysis for beta-diketon cleavage by the non-heme Fe2+-dependent dioxygenase Dke1. J. Am. Chem. Soc. 2005, 127, 12306-12314.

33. Allen, P. M.; Hess, U.; Foote, C. S.; Baizer, M. M.; Electrogenerated bases IV. Reaction of electrogenerated superoxide with some carbon acids. Synthetic Communications 1982, 12, 123129.

34. Comba, P.; Lee, Y.M.; Nam, W.; Waleska, A. Catalytic oxidation of alkanes by iron bispidine complexes and dioxygen: oxygen activation versus autoxidation. Chem. Commun. 2014, 50, 412.

35. (a) Kice, J. L.; Bowers K. W. Mechanism of disproportionation of sulfinic acids. J. Am. Chem. Soc., 1962, 84, 605 (b) Kice, J. L.; Bowers, K. W. Mechanisms of reactions of sulfinic acids. II. The reaction of $p$-tolyl disulphide with $p$-tolylsulfinic acid. J. Am. Chem. Soc. 1962, 84, 2384. 
38. Teles, J. H.; Hermans, I.; Franz, G.; Sheldon, R. A. Ullmann's Encyclopedia of Industrial Chemistry, Wiley-VCH Verlag GmbH \& Co. KGaA, 2015, DOI: 10.1002/14356007.a18_261.pub2.

36. Bagiyan, G. A.; Koroleva, I. K.; Soroka, N. V.; Ufimtsev, A. V. Oxidation of Thiol Compounds by Molecular Oxygen in Aqueous Solutions. Russ. Chem. Bull. 2003, 52, 1135-1141.

37. Wallace, T. J.; Schriesheim, A. The base-catalysed oxidation of aliphatic and aromatic thiols and disulfides to sulphonic acids. Tetrahedron. 1965, 21, 2271-2280. 
TOC Graphic

Structural biomimetic complexes

- similar coordination $\checkmark$

- similar properties $\checkmark$

Functional biomimetic catalysts

- similar substrates $X$

- similar conditions $X$

- similar function $X$






\section{A Facially Coordinating Tris-Benzimidazole Ligand for Nonheme Iron Enzyme Models: Biomimetic or Radical Aerobic Oxidation?}

Parami S. Gunasekera, ${ }^{\dagger}$ Preshit C. Abhyankar, ${ }^{\dagger}$ Samantha N. MacMillan, ${ }^{\S}$ David C. Lacy ${ }^{* \dagger}$

t Department of Chemistry, University at Buffalo, State University of New York, Buffalo, New York 1426o, United States.

$\S$ Department of Chemistry and Chemical Biology, Cornell University, Ithaca, New York 14853, United States

E-mail: DCLacy@buffalo.edu

\begin{tabular}{|c|c|}
\hline Contents & Page \\
\hline General considerations & S2 \\
\hline Crystallographic methods & S2 \\
\hline Computational methods & S2 \\
\hline Synthesis and characterization of $\mathbf{2 b i m}$ & S2 \\
\hline Synthesis and characterization of Tbim & S3 \\
\hline Figure S1: ${ }^{1} \mathrm{H}$ NMR spectrum of Tbim in MeCN- $d_{3}{ }^{*}$ & S3 \\
\hline Figure S2: ${ }^{13} \mathrm{C}$ NMR spectrum of Tbim in chloroform- $d^{*}$ & S3 \\
\hline Figure S3: ATR-FTIR spectrum of Tbim & $\mathrm{S} 4$ \\
\hline Synthesis and characterization of $\mathbf{1}$ & $\mathrm{S}_{5}$ \\
\hline Figure S4: ${ }^{1} \mathrm{H}$ NMR spectrum of 1 in $\mathrm{MeCN}-d_{3}{ }^{*}$ & $\mathrm{~S}_{5}$ \\
\hline 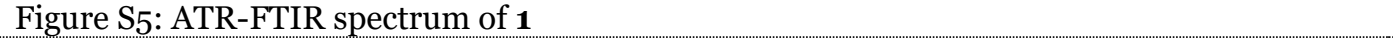 & $\mathrm{S}_{5}$ \\
\hline Synthetic details and characterization for 2 & S6 \\
\hline Figure S6: ${ }^{1} \mathrm{H}$ NMR spectrum of 2 in $\mathrm{MeOH}-d_{4}{ }^{*}$ & S6 \\
\hline Figure S7: ATR-FTIR spectrum of 2 & S6 \\
\hline Synthesis and characterization of $[3]\left[\mathrm{BPh}_{4}\right]_{2}$ & S7 \\
\hline Figure S8: ${ }^{1} \mathrm{H}$ NMR spectrum of $[3]\left[\mathrm{BPh}_{4}\right]_{2}$ in DMSO- $d_{6}{ }^{*}$ & S7 \\
\hline Figure S9: ATR-FTIR spectrum of $[3]\left[\mathrm{BPh}_{4}\right]_{2}$ & S7 \\
\hline Synthesis and characterization of $[3][\mathrm{OTf}]_{2}$ and $[4][\mathrm{OTf}]$ & S8 \\
\hline Figure S10: ${ }^{1} \mathrm{H}$ NMR spectrum of $[3][\mathrm{OTf}]_{2}$ in $\mathrm{MeCN}-d_{3}{ }^{*}$ & S8 \\
\hline Figure S11: ${ }^{19} \mathrm{~F}\left\{{ }^{1} \mathrm{H}\right\}$ NMR spectrum of $[3][\mathrm{OTf}]_{2}$ in $\mathrm{MeCN}-d_{3}$ & S8 \\
\hline Figure S12: ${ }^{19} \mathrm{~F}\left\{{ }^{1} \mathrm{H}\right\}$ NMR spectrum of $1: 1$ mixture of Tbim and $\mathrm{Fe}(\mathrm{OTf})_{2} \cdot 2 \mathrm{~V}$ & S9 \\
\hline Figure S13: ATR-FTIR spectrum of [3][OTf $]_{2}$ & S9 \\
\hline Figure S14: ATR-FTIR spectrum of [4][OTf] with MeCN stretches & S9 \\
\hline Figure S15: ${ }^{1} \mathrm{H}$ NMR spectrum of a mixture of $[3][\mathrm{OTf}]_{2}$ and $[4][\mathrm{OTf}]$ in $\mathrm{MeCN}-d_{3}{ }^{*}$ & S10 \\
\hline Figures S16. XRD determined connectivity structure of $[3]^{2+}$ & S10 \\
\hline Procedure for determining Fe(II):Tbim mole ratio & S11 \\
\hline Figure S17: Plot of optimal mole ratio for in situ preparation of [4] ${ }^{+}$ & S11 \\
\hline Procedure for $\mathrm{p} K_{\mathrm{a}}$ measurements & S12 \\
\hline Figure S18: Spectra and plots used for $\mathrm{p} K_{\mathrm{a}}$ measurements & S12 \\
\hline Table S1: $\mathrm{p} K_{\mathrm{a}}$ table for Figure S19 & S13 \\
\hline Figures S19: Comparison of ligand conjugate acid $\mathrm{p} K$ a to histidine & S13 \\
\hline Procedures for catalytic oxidation of LiPhmal & S14 \\
\hline Table S2. oxidation of Li[Phmal] results. & S14 \\
\hline Figure S20: GC trace for HPhmal and its oxidation products & S14 \\
\hline Procedures for catalytic oxidation of sodium thiocresol & S15 \\
\hline Table S3: Results from catalytic aerobic oxidation of sodium thiocresol & S15 \\
\hline Characterization data for oxidation products & $\mathrm{S} 16-\mathrm{S} 18$ \\
\hline Determination of Schlenk equilibrium from DFT & S19 \\
\hline Table 4: DFT computed Gibbs's free energies for Schlenk equilibrium & S19 \\
\hline References & S19-S2C \\
\hline
\end{tabular}




\section{EXPERIMENTAL}

\section{General considerations}

All chemicals were used as purchased from chemical vendors unless otherwise noted. Manipulations of air sensitive compounds were carried out in a nitrogen filled Genesis VAC glovebox or using Schlenk techniques to ensure dry and oxygen-free conditions. Dry, oxygen-free solvents were obtained from a PPT solvent purification system and were purified and stored over $3 \AA$ molecular sieves. The acetonitrile used for catalysis was further dried by passing through alumina and stored over $3 \AA$ molecular sieves. The sieves were activated at $200^{\circ} \mathrm{C}$ under vacuum for 48 hours prior to use. NMR experiments were carried out on Varian Mercury $300 \mathrm{MHz}$ or Inova 400 MHz spectrometers. ATR-FTIR spectra were collected using a Bruker Alpha IR spectrometer with the "ATR Platinum" insert adapter (diamond crystal), which was stored inside a nitrogen filled VAC Atmospheres glovebox. UV-vis spectra were collected using an 8154 Agilent Spectrophotometer. The $\mathrm{pH}$ of the buffer solutions was measured with Mettler Toledo FiveEasy $\mathrm{pH}$ meter and a Mettler Toledo glass electrode lE438-IP67 at $25{ }^{\circ} \mathrm{C}$. HRMS was performed using a FT-ICR Brucker $12 \mathrm{~T}$ mass spectrometer. GC-MS analysis was performed with a HP 5890 Series II GC containing a J\&W Scientific, Inc. column $(30 \mathrm{~m} \times 0.250 \mathrm{~mm})$ with a $0.10 \mu \mathrm{m}$ thin film of phenyl arylene polymer coupled to a HP 5972 Series mass selective detector. Volumetric measurements were carried in analytic grade glassware. All aqueous solutions were prepared using distilled, deionized water. CHN combustion analysis was performed by Robertson Microlit Laboratories, NJ USA. Fe(OTf $)_{2} \cdot 2 \mathrm{MeCN},{ }^{1}$ bis(benzimidazole-2-yl)methane, ${ }^{2}$ 2-chloromethyl-1-ethylbenzimidazole, ${ }^{3}$ Li[Phmal], ${ }^{4}$ ethyl benzoylformate, ${ }^{5}$ sodium thiocresol, ${ }^{6} p$-toluenesulfinic acid,7 S-(4-methylphenyl) 4-methylbenzenesulfonothioate ${ }^{8}$ and 1,2-di- $p$ tolyldisulfane ${ }^{9}$ were prepared according to literature procedures.

\section{Crystallographic methods}

Low-temperature X-ray diffraction data for [Fe $\{$ Tbim $\left.\}(\mathrm{MeCN})_{2}(\mathrm{OTf})\right][\mathrm{OTf}]$ (Rlacy28), $\left[\mathrm{Fe}\{\mathbf{T b i m}\}(\mathrm{OAc})_{2}\right]$ (Rlacy31) and [Fe $\{$ Tbim $\left.\}(\mathrm{Cl})_{2}\right]$ (Rlacy37) were collected on a Rigaku XtaLAB Synergy diffractometer coupled to a Rigaku. Rlacy28 was treated as a racemic twin; the explicit refinement of the Flack parameter yielded a value of $0.450(4)$. Hypix detector with $\mathrm{Cu} \mathrm{Ka}$ radiation $(\lambda=1.54184 \AA$ ) from a PhotonJet micro-focus X-ray source at $100 \mathrm{~K}$ for Rlacy28 and Rlacy37 and $253 \mathrm{~K}$ for Rlacy31. The diffraction images were processed and scaled using the CrysAlisPro software. ${ }^{10}$ The structures were solved through intrinsic phasing using SHELXT ${ }^{11}$ and refined against $\mathrm{F}^{2}$ on all data by full-matrix least squares with SHELXL ${ }^{12}$ following established refinement strategies. ${ }^{13}$ All non-hydrogen atoms were refined anisotropically. All hydrogen atoms were included in the model at geometrically calculated positions and refined using a riding model. The isotropic displacement parameters of all hydrogen atoms were fixed to 1.2 times the $\mathrm{U}_{\text {eq }}$ value of the atoms they are linked to (1.5 times for methyl groups).

\section{Computational methods}

All DFT calculations were performed in ORCA $4.0^{14}$ using the B3LYP functional with atom-pairwise dispersion correction with Becke-Johnson damping ${ }^{15,16}$ and def2-SVP ${ }^{17}$ basis set. The conductor-like polarizable continuum model (C-PCM) implicit solvation model was used to incorporate solvent effects. All thermochemical calculations were performed at standard conditions ( $1 \mathrm{~atm}$ pressure and $298.15 \mathrm{~K}$ ). The optimized gas-phase geometries of all molecules were computed and minima were confirmed by the absence of imaginary frequencies. Optimized geometries of $\mathrm{MeCN}$, [OTf] $]^{-}\left[\mathrm{Fe}(\mathrm{MeCN})_{4}(\mathrm{OTf})_{2}\right]$, and the free ligand (Tbim) solvated in MeCN were obtained similarly. The single point energies of $\left[\mathrm{Fe}(\mathrm{Tbim})(\mathrm{MeCN})_{2}(\mathrm{OTf})\right]^{-}$and $[\mathrm{Fe}(\mathrm{Tbim})]^{2+}$ solvated in $\mathrm{MeCN}$ were obtained using the cartesian coordinates of the gas-phase optimized molecules. These single point energies were utilized to calculate their solvation Gibb’s free enthalpies.

\section{Synthesis}

Synthesis of Bis(1-methylbenzimidazol-2-yl)methane (2bim): In a glovebox, a $500 \mathrm{~mL}$ Schlenk flask equipped with a stir bar was charged with bis(benzimidazole-2-yl)methane (2.73 g, $11.0 \mathrm{mmol})$ and dissolved in $150 \mathrm{~mL}$ of dry DMA. The solution was stirred for 10 minutes. Careful addition of $\mathrm{KH}$ (0.972 g, $24.2 \mathrm{mmol})$ to the solution (CAREFUL: slow addition necessary,) over fifteen minutes caused the solution to turn red and the solution was stirred for an additional 30 minutes after which effervescence ceased. The flask was removed from the glovebox and blanketed with argon on a Schlenk line. Methyl iodide $(1.25 \mathrm{~mL}, 24.6 \mathrm{mmol})$ was added dropwise to the reaction mixture (by hand with a syringe, $\approx 3$ minutes) and the solution was stirred overnight at room temperature. Open to air, the reaction mixture was poured into $300 \mathrm{~mL}$ of rapidly stirring water and the resulting solid was filtered, washed with $50 \mathrm{~mL}$ of water and dried under vacuum (2.05 g, 68\% yield). ${ }^{1} \mathrm{H}$ NMR data matches with the literature reported values. ${ }^{2}{ }^{1} \mathrm{H}$ NMR (Chloroform- $d$, $\left.300 \mathrm{MHz}\right): \delta 3.88\left(\mathrm{~s}, 6 \mathrm{H}, \mathrm{CH}_{3}\right), 4.67\left(\mathrm{~s}, 2 \mathrm{H}, \mathrm{CH}_{2}\right)$, 7.25 (m, 6H, aromatic), 7.71 (m, 2H, aromatic).

Synthesis of 2,2'-(2-(1-ethylbenzimidazol-2yl)ethane-1,1-diyl)bis(1-methylbenzimidazole) (Tbim): In a glovebox, a $100 \mathrm{~mL}$ Schlenk tube equipped with a stir bar was charged with $\mathbf{2 b i m}(0.858 \mathrm{~g}, 3.11 \mathrm{mmol}$ ) to which $20 \mathrm{~mL}$ of dry THF was added. The flask was removed from the glovebox and blanketed with argon on a Schlenk line. The solution was cooled to $-78^{\circ} \mathrm{C}$, after which $n$-butyllithium (1.37 mL, $3.46 \mathrm{mmol}, 2.5 \mathrm{M}$ in hexane) was added to the solution via a syringe and the reaction mixture was stirred for 1 hour (color change from brown to yellow brown). In a glovebox, 2-chloromethyl 1-ethylbenzimidazole (0.587 g, $3.02 \mathrm{mmol})$ charged in a Schlenk 
flask was dissolved in $20 \mathrm{~mL}$ of dry THF and stirred for 10 minutes. The solution was taken out of the glovebox and under Schlenk conditions the solution was added dropwise to the reaction mixture containing 2 bim and $n$ butyllithium via cannula transfer. The reaction vessel was left in the cold bath overnight to slowly warm to room temperature with stirring. The reaction mixture was opened to air and quenched with $10 \mathrm{~mL}$ of water, volatiles were removed, and the aqueous layer was extracted with ethyl acetate $(3 \times 30 \mathrm{~mL})$. The organic layer was dried over anhydrous $\mathrm{Na}_{2} \mathrm{SO}_{4}$ and filtered. The filtrate was evaporated to obtain a yellow orange solid, which was further purified by washing with diethyl either $(10 \mathrm{~mL})$ and then hexane $(10 \mathrm{~mL})$, and repeating this process two more times. The ligand was obtained as a solid that was purified by column chromatography [ethyl acetate/methanol/ammonium hydroxide (80:19:1)]. Batches varied in color from off white, light pink, to faint yellow (1.14 g, 84\% yield). ${ }^{1} \mathrm{H}$ NMR (MeCN- $\left.d_{3}, 300 \mathrm{MHz}\right): \delta 1.38\left(\mathrm{t}, \mathrm{J}=7.2 \mathrm{~Hz}, 3 \mathrm{H},-\mathrm{CH}_{3}\right), 3.75\left(\mathrm{~s}, 6 \mathrm{H}, \mathrm{NCH}_{3}\right)$, 4.04 (d, J = 7.2 Hz, 2H, - $\mathrm{CH}_{2}-$ ), 4.30 (q, J = 7.2 Hz, 2H, $\mathrm{NCH}_{2}-$ ), 5.74 (t, J = 7.2 Hz, 1H, - HC meso carbon), 7.17 (dd, $\mathrm{J}=13.7,7.5 \mathrm{~Hz}, 2 \mathrm{H}$, aromatic), 7.26 (d, $\mathrm{J}=7.1 \mathrm{~Hz}, 1 \mathrm{H}$, aromatic), 7.4 (d, $\mathrm{J}=9.2 \mathrm{~Hz}, 2 \mathrm{H}$, aromatic), 7.54 (dt, $\mathrm{J}=15.2,7.4 \mathrm{~Hz}, 3 \mathrm{H}$, aromatic). ${ }^{13} \mathrm{C}$ NMR (Chloroform- $d, 101 \mathrm{MHz}$ ): $\delta$ 15.13, 30.05, 36.33, 38.37, 109.34, 109.56, $118.97,119.92,122.22,122.30,134.71,136.02,142.38,142.55,151.85,152.34 . \mathrm{mp}: 205^{-} 208{ }^{\circ} \mathrm{C}^{2}$ ATR-FTIR (cm ${ }^{-}$ 1): 3052, 2969, 1614, 1457, 1270, 1006, 803, 749, 736, 556, 415. HRMS (LDI/FT-ICR) m/z: Calcd for [2(Tbim)+Na]+ 891.43356; Found. 891.43654, Calcd for [Tbim+H] ${ }^{+} 435.22972$; Found. 435.23023.

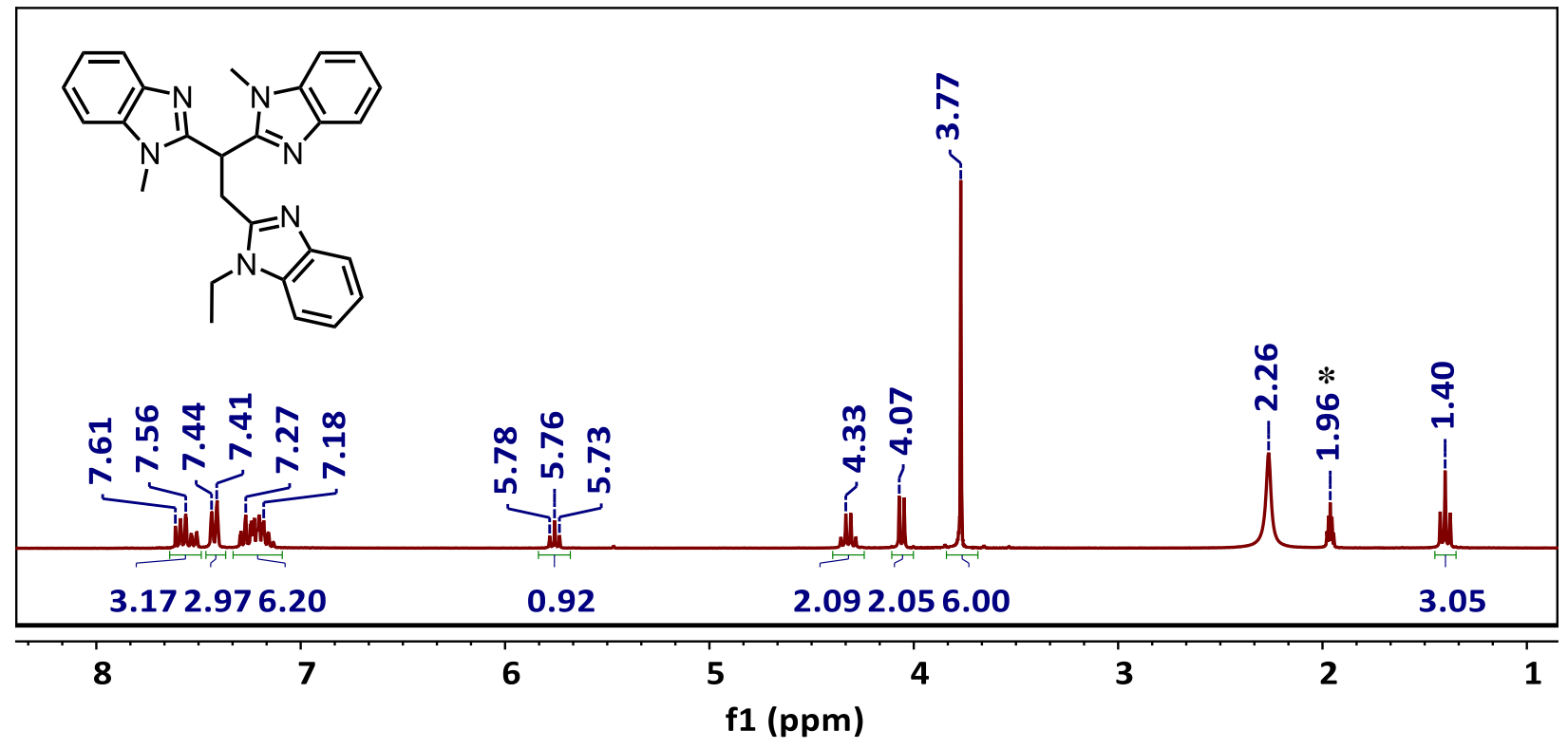

Figure S1: ${ }^{1} \mathrm{H} \mathrm{NMR}$ spectrum of Tbim in $\mathrm{MeCN}-\mathrm{d}_{3}{ }^{*}$

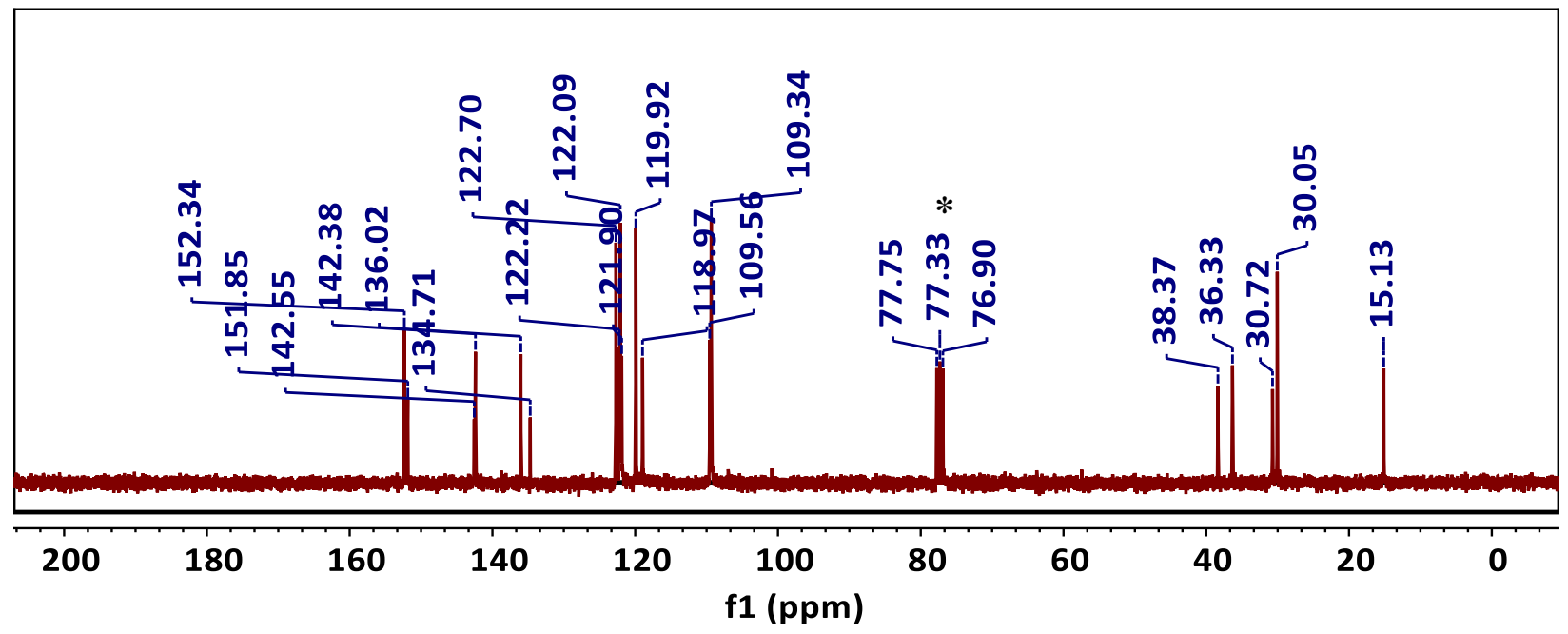

Figure S2: ${ }^{13} \mathrm{C}$ NMR spectrum of Tbim in chloroform- $d^{*}$ 


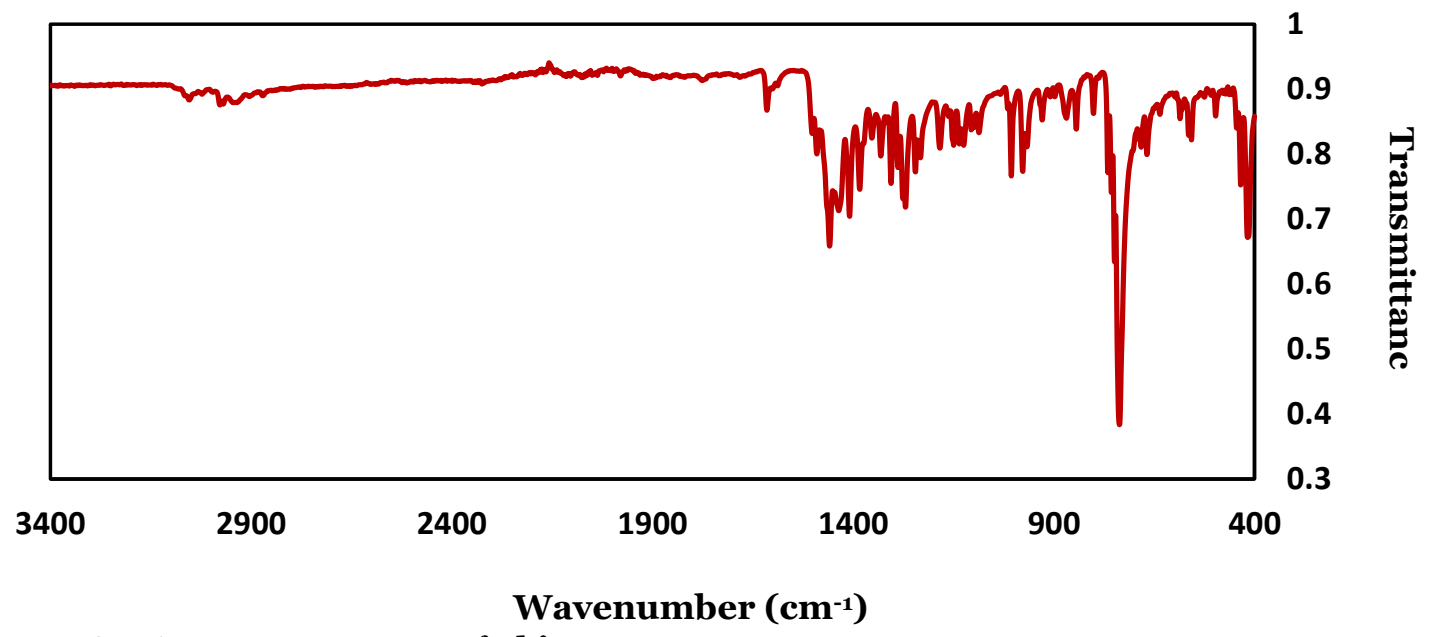

Figure S3: ATR-FTIR spectrum of Tbim 


\section{Synthesis and characterization of 1,2 , and 3}

[Fe $\{$ Tbim $\left.\}(\mathrm{OAc})_{2}\right]$ (1): $\mathrm{Fe}(\mathrm{OAc})_{2}(40 \mathrm{mg}, 0.23 \mathrm{mmol})$ and Tbim (100 mg, $0.230 \mathrm{mmol}$ ) was stirred in $15 \mathrm{~mL}$ of dry acetonitrile for 1 hour under nitrogen in a glovebox. The solution was removed in vacuo and dissolved in 10 $\mathrm{mL}$ of dry dichloromethane. Diffusion of diethyl ether into the reaction mixture gave yellow microcrystalline solids (118 mg, isolated yield: 84\%). Crystals suitable for XRD were obtained by layering a dichloromethane solution of 1 under diethyl ether. ATR-FTIR $\left(\mathrm{cm}^{-1}\right)$ : 2309, 2279, 1454, 1282, 1236, 1221, 1149, 1028, 748, 634, 1564, 1483, 1409, 1336, 1007, 734, 673. UV-vis (DCM, [ $\left.\left.\varepsilon \mathrm{M}^{-1} \mathrm{~cm}^{-1}\right]\right): \lambda_{\max }=209 \mathrm{~nm}(944) .{ }^{1} \mathrm{H}$ NMR $\left(\mathrm{MeCN}-d_{3}\right.$, $300 \mathrm{MHz}$ ): $\delta$-20.02, $-0.59,-0.20,1.59$, 3.60, 3.93, 4.20, 4.68, 5.62, 5.86, 6.93, 7.20, 7.36, 7.58, 7.77, 8.76, 21.48, 21.77, 88.30. Anal. Calcd (found) for 1•0.5 $\mathrm{CH}_{2} \mathrm{Cl}_{2}\left(\mathrm{C}_{31.5} \mathrm{H}_{32} \mathrm{ClFeN}_{6} \mathrm{O}_{4}\right)$ : C, 58.12 (58.36); H, 5.11 (5.16); N, 12.91 (13.05). Evans' method (MeCN- $\left.d_{3}, 300 \mathrm{MHz}, 298 \mathrm{~K}\right) \mu_{\text {eff }}=5.31 \mu_{\mathrm{B}}$.

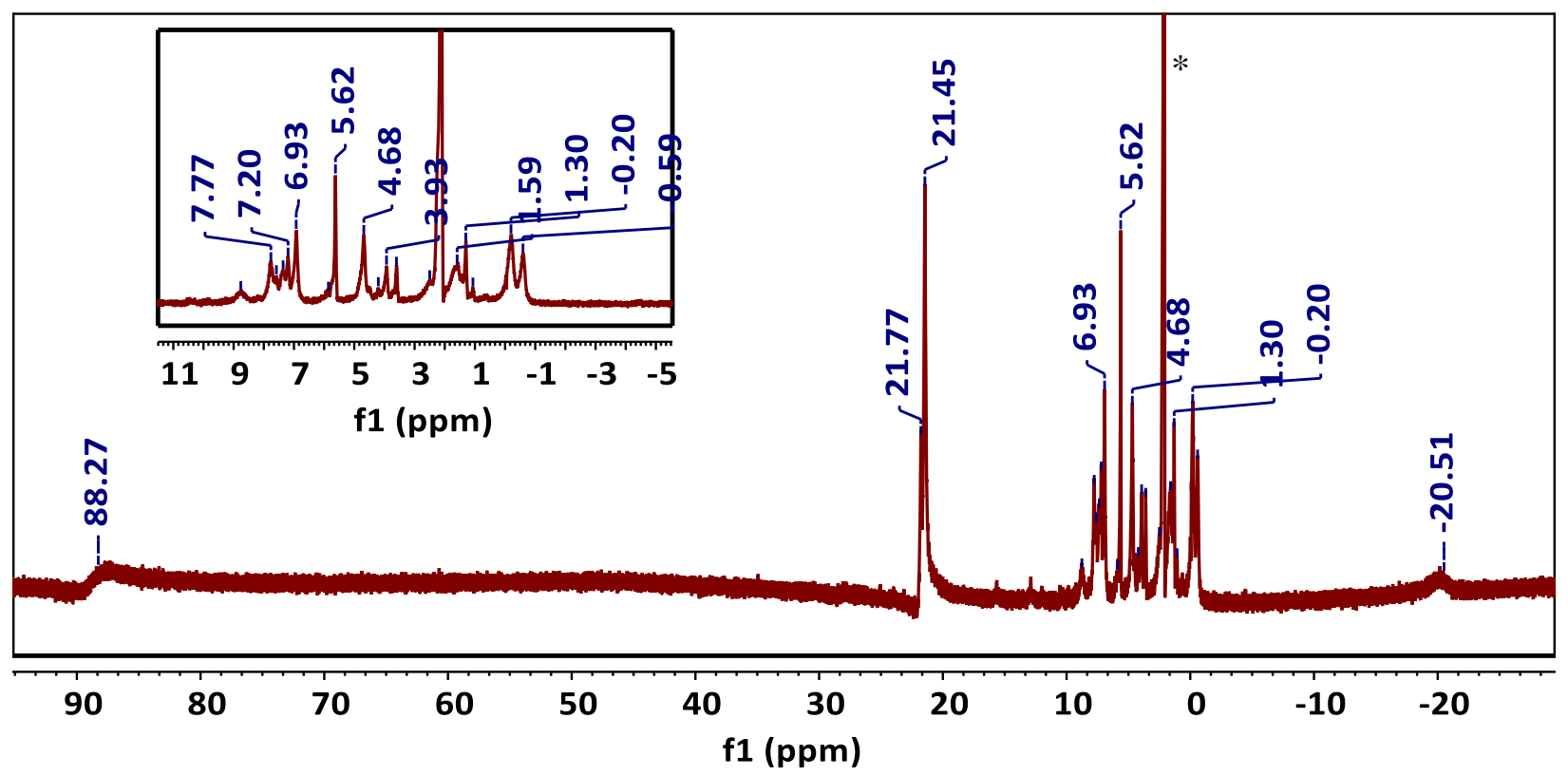

Figure S4: ${ }^{1} \mathrm{H}$ NMR spectrum of 1 in $\mathrm{MeCN}-d_{3}{ }^{*}$

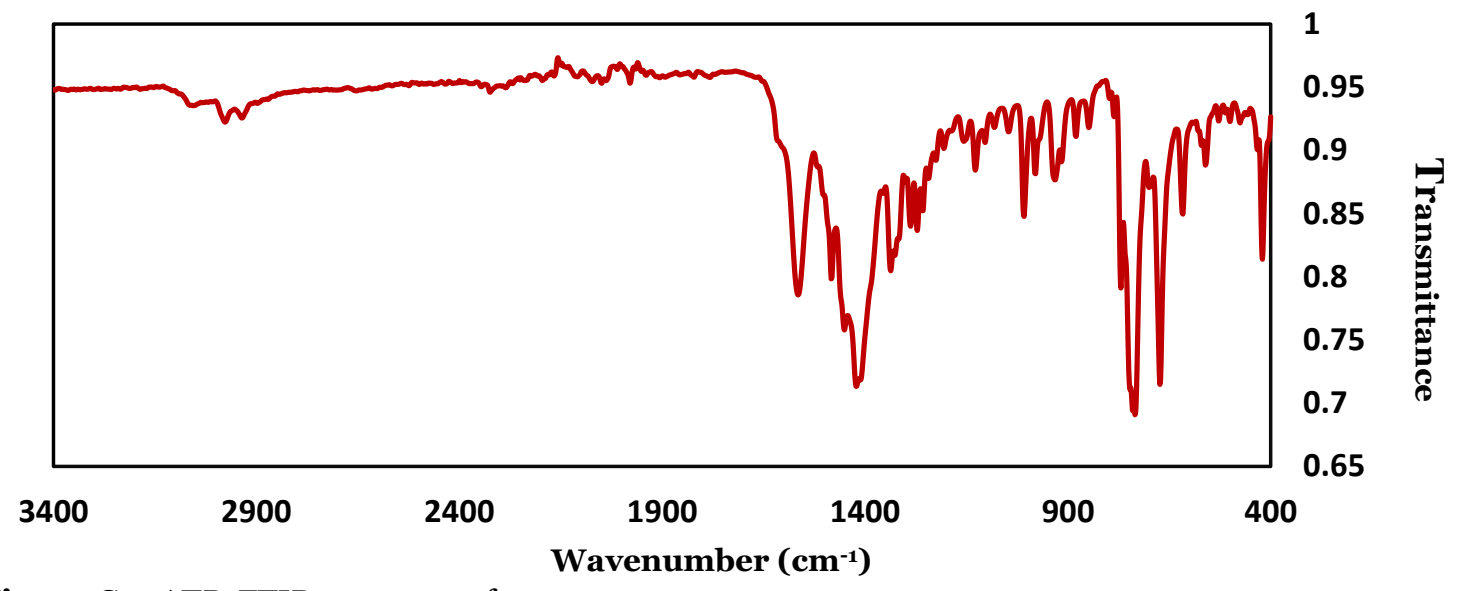

Figure S5: ATR-FTIR spectrum of 1 
[Fe $\{$ Tbim $\left.\}(C l)_{2}\right]$ (2): Anhydrous $\mathrm{FeCl}_{2}(12 \mathrm{mg}, 0.092 \mathrm{mmol})$ and Tbim (40 $\mathrm{mg}$, $0.092 \mathrm{mmol}$ ) were stirred together in $5 \mathrm{~mL}$ of dry acetonitrile in a nitrogen filled glovebox. The suspension was treated with methanol dropwise until a homogenous solution was obtained. The solution was further stirred for 1 hour and the resulting reaction mixture was filtered. Diffusion of diethyl ether to the reaction mixture produced colorless crystals of 2 (32 mg, 61\% yield). ATR-FTIR (cm-1): 3021, 2978, 1616, 1450, 1402, 1332, 1283, 1149, 1009, 739, 560. ${ }^{1} \mathrm{H}$ NMR $\left(\mathrm{MeOH}-d_{4}, 4 \mathrm{OO} \mathrm{MHz}\right): \delta$-0.54, $-0.32,1.14,4.61,5.94,6.67,8.13,8.91,9.61,9.74,10.22,11.54,11.75,12.30,12.75$, 23.66, 25.01, 27.50, 28.29. Anal. Calcd (found) for $2 \cdot 0.5 \mathrm{CH}_{2} \mathrm{Cl}_{2}\left(\mathrm{C}_{31.5} \mathrm{H}_{32} \mathrm{ClFeN}_{6} \mathrm{O}_{4}\right): \mathrm{C}, 58.12$ (58.36); H, 5.11 (5.16); N, 12.91 (13.05). HRMS (LDI/FT-ICR) m/z: Calcd for [(2)-Cl] ${ }^{+}$525.12569; Found 525.12707. Evans' method $\left(\mathrm{MeOH}-d_{4}, 300 \mathrm{MHz}, 298 \mathrm{~K}\right) \mu_{\mathrm{eff}}=5.79 \mu_{\mathrm{B}}$.

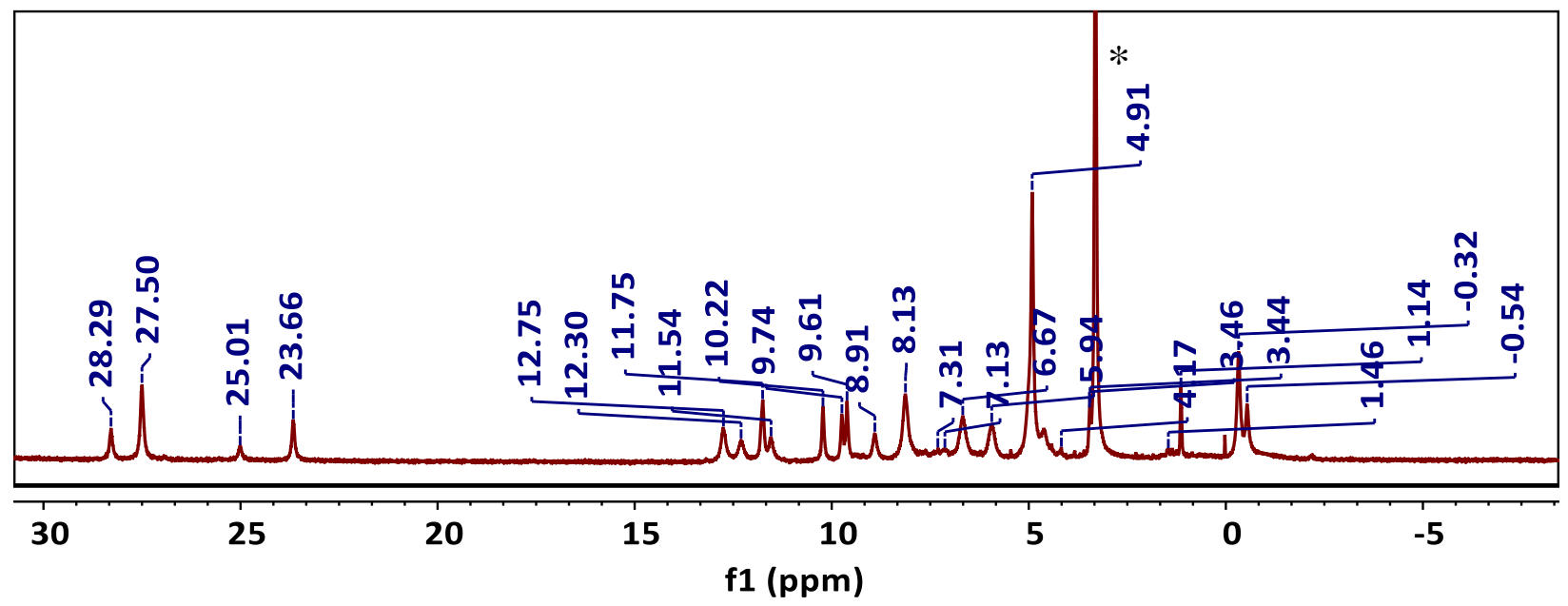

Figure S6: ${ }^{1} \mathrm{H}$ NMR spectrum of 2 in $\mathrm{MeOH}-d_{4}{ }^{*}$



Figure S7: ATR-FTIR spectrum of 2 
$\left[\mathrm{Fe}\{\boldsymbol{T} \boldsymbol{T b i m}\}_{2}\right]\left[\mathrm{BPh}_{4}\right]_{2}\left([3][\mathrm{BPh}]_{4}\right): \mathrm{Fe}(\mathrm{OAc})_{2}(8 \mathrm{mg}, 0.05 \mathrm{mmol})$ and Tbim (20 $\left.\mathrm{mg}, 0.046 \mathrm{mmol}\right)$ were mixed together in $1 \mathrm{~mL}$ of acetonitrile for 30 minutes. Once the solution became homogenous, the solvent was removed in vacuo and the resulting residue was taken up in $5 \mathrm{~mL}$ of methanol. The solution was stirred with $\mathrm{NaBPh}_{4}(16$ $\mathrm{mg}, 0.046 \mathrm{mmol}$ ) and a yellow solid formed that was isolated by filtration and redissolved in a minimum amount of dichloromethane from which crystalline $[3]\left[\mathrm{BPh}_{4}\right]_{2}$ precipitated over 24 hours (18.2 $\mathrm{mg}, 98 \%$ yield). (Figure S16) ATR-FTIR (cm-1): 3052, 2978, 1477, 1448, 1264, 838, 730, 703, 610. ${ }^{1} \mathrm{H}$ NMR (DMSO- $\left.d_{6}, 400 \mathrm{MHz}\right): \delta$ $-43.39,-0.51,-0.04,1.76,2.07,2.29,3.02,3.59,3.86,4.54,6.26,6.78,6.89,7.15,7.35,7.40,7.66,8.45,9.16$, 9.81, 11.64, 12.65, 24.12, 24,60, 27.28, 27.74. Evans' method (MeCN-d $\left.d_{3}, 300 \mathrm{MHz}, 298 \mathrm{~K},\right)$, $\mu_{\mathrm{eff}}=5.07 \mu_{\mathrm{B}}$.

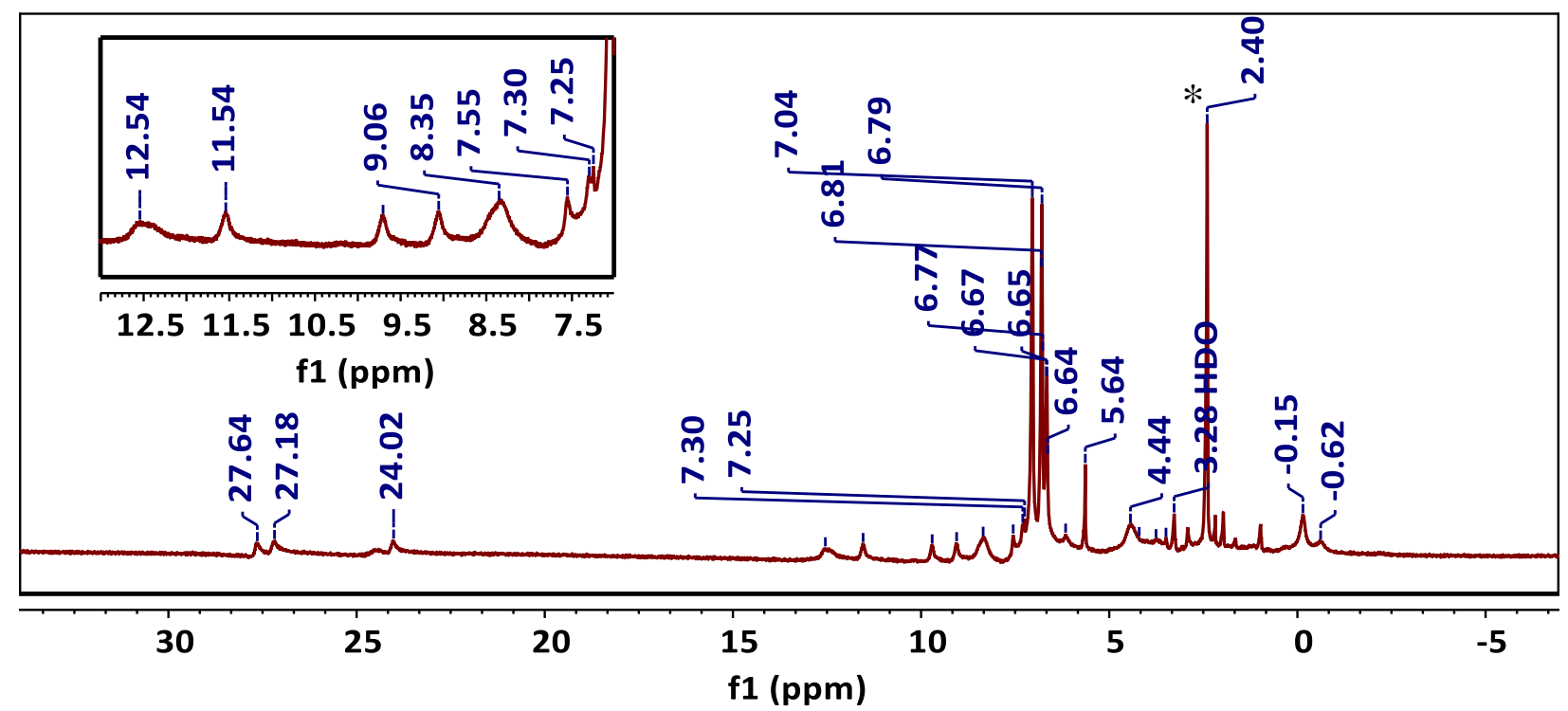

Figure S8: ${ }^{1} \mathrm{H}$ NMR spectrum of $[3]\left[\mathrm{BPh}_{4}\right]_{2}$ in DMSO- $d_{6}{ }^{*}$

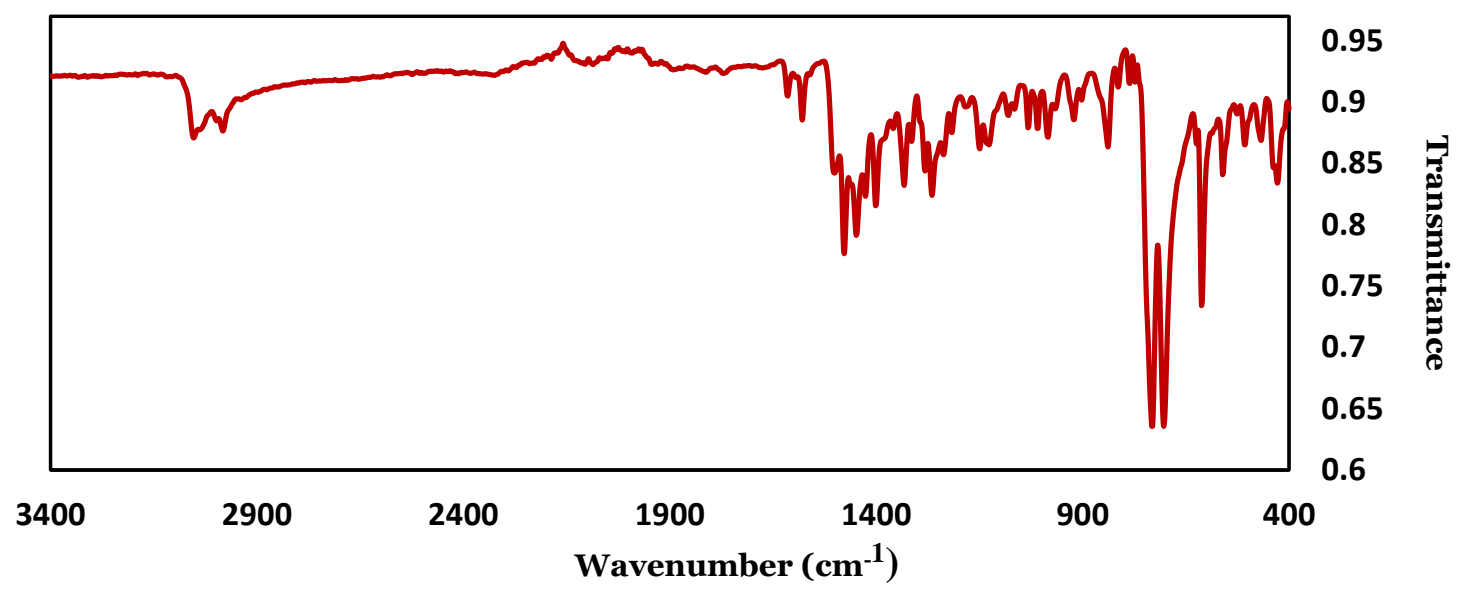

Figure S9: ATR-FTIR spectrum of $[3]\left[\mathrm{BPh}_{4}\right]_{2}$ 


\section{Preparation of 4}

The following procedures are nearly identical, but differ slightly in workup. Isolation of [4] $]^{+}$free from $[3]^{2+}$ was not accomplished in this work. Synthesis was performed in a nitrogen filled glovebox.

$\left[\mathrm{Fe}\{\boldsymbol{T} \text { bim }\}_{2}\right][\mathrm{OTf}]_{2}\left([\mathbf{3}][\mathrm{OTf}]_{2}\right): \mathrm{Fe}(\mathrm{OTf})_{2} \cdot 2 \mathrm{MeCN}(24 \mathrm{mg}, 0.055 \mathrm{mmol})$ was stirred in $6 \mathrm{~mL}$ of acetonitrile and the ligand Tbim $(25 \mathrm{mg}, 0.055 \mathrm{mmol})$ and was added to the solution. The reaction was stirred for 1 hour and was filtered. The filtrate was reduced to $1 \mathrm{~mL}$ in volume. Crystallization of the acetonitrile reaction mixture by diethyl ether diffusion over 16 hours produced colorless microcrystalline [3][OTf $]_{2}(20 \mathrm{mg}, 56 \%$ yield). Alternatively, the reaction of two equivalents of ligand $(30 \mathrm{mg}, 0.069 \mathrm{mmol})$ with one equivalent of the metal salt $\mathrm{Fe}(\mathrm{OTf})_{2}(12 \mathrm{mg}$, $0.035 \mathrm{mmol})$ in $5 \mathrm{~mL}$ of acetonitrile also produced colorless microcrystals of [3][OTf $]_{2}(25 \mathrm{mg}, 60 \%)$. ATR-FTIR $\left(\mathrm{cm}^{-1}\right): 1452,1405,1254,1153,1028,741,637 .{ }^{1} \mathrm{H} \mathrm{NMR}\left(\mathrm{MeCN}_{3}, 300 \mathrm{MHz}\right): \delta$-45.93, -8.96, -2.10, -0.45, 4.71, 5.05, 5.62, 7.74, 7.97, 8.93, 9.11, 9.63, 10.27, 11.78, 12.49, 12,83, 13.61, 18.68, 23.81, 24.01, 27.05, 27.63, 27.93, 51.74. ${ }^{19} \mathrm{~F}\left\{{ }^{1} \mathrm{H}\right\}$ NMR $\left(\mathrm{MeCN}_{3},{ }_{3}, 282.33 \mathrm{MHz}\right): \delta-79.76$. HRMS (LDI/FT-ICR) m/z: Calcd for $\{[3][\mathrm{OTf}]\}^{+}$ 1073.33076; Found 1073.32556. Anal. Calcd (found) for [3][OTf] $]_{2} \mathrm{C}_{56} \mathrm{H}_{5} 2 \mathrm{~N}_{12} \mathrm{O}_{6} \mathrm{~S}_{2} \mathrm{~F}_{6} \mathrm{Fe}$ : C, 54.99 (54.43); H, 4.29 (4.18); N, 13.74 (14.0). Evans' method ( $\mathrm{MeCN}-d_{3}, 300 \mathrm{MHz}, 298 \mathrm{~K}$, ), $\mu_{\text {eff }}=5.06 \mu_{\mathrm{B}}$.

$\left[\right.$ Fe $\{$ Tbim $\left.\}(\mathrm{MeCN})_{2}(\mathrm{OTf})\right][\mathrm{OTf}]$ ([4]][OTf]): $\mathrm{Fe}(\mathrm{OTf})_{2} \cdot 2 \mathrm{MeCN}(36 \mathrm{mg}, 0.083 \mathrm{mmol})$ and Tbim (30 mg, o.069 $\mathrm{mmol}$ ) was stirred in $4.5 \mathrm{~mL}$ of acetonitrile for 1 hour. The resulting solution was pumped off until only trace amounts of acetonitrile remained. The solid/residue was dissolved in $4.5 \mathrm{~mL}$ of dichloromethane and was stirred for 1 hour. The solution was filtered to remove unreacted $\mathrm{Fe}(\mathrm{OTf})_{2}$ and $\left[\mathrm{Fe}\{\mathbf{T b i m}\}_{2}\right][\mathrm{OTf}]_{2}$. A drop cast IR of the dichloromethane filtrate indicate the presence of [4][OTf] in solution. Diethyl ether diffusion into the reaction filtrate formed colorless crystals of [4][OTf] (26 mg, 43\% yield) accompanied with microcrystalline [3][OTf $]_{2}$. ATR-FTIR ( $\left.\mathrm{cm}^{-1}\right)$ : for crystalline [4][OTf] 2978, 2931, 2309, 2279, 1657, 1616, 1596, 1454, 1282, 1236, 1221, 1149, 1028, 748, 634. ${ }^{1} \mathrm{H}$ NMR (MeCN-d $\left.d_{3}, 400 \mathrm{MHz}\right): \delta$-8.95, -2.97 -2.10, 3.27, 3.42, 7.72, 8.69, 8.89, 9.70, 11.94, $13.58,15.84,18.65,23.94,26.67,26.98,32.00 .{ }^{19} \mathrm{~F}\left\{{ }^{1} \mathrm{H}\right\}$ NMR (MeCN- $\left.d_{3}, 282.33 \mathrm{MHz}\right): \delta-72.94 . \mathrm{CHN}$ and HRMS always contained significant amounts of $[3]^{2+}$. HRMS (LDI/FT-ICR) $\mathrm{m} / \mathrm{z}$ : Calcd for $\{\mathrm{Fe}+\mathbf{T b i m}+\mathrm{OTf}\}^{+}$ 639.10886; Found 639.10884.

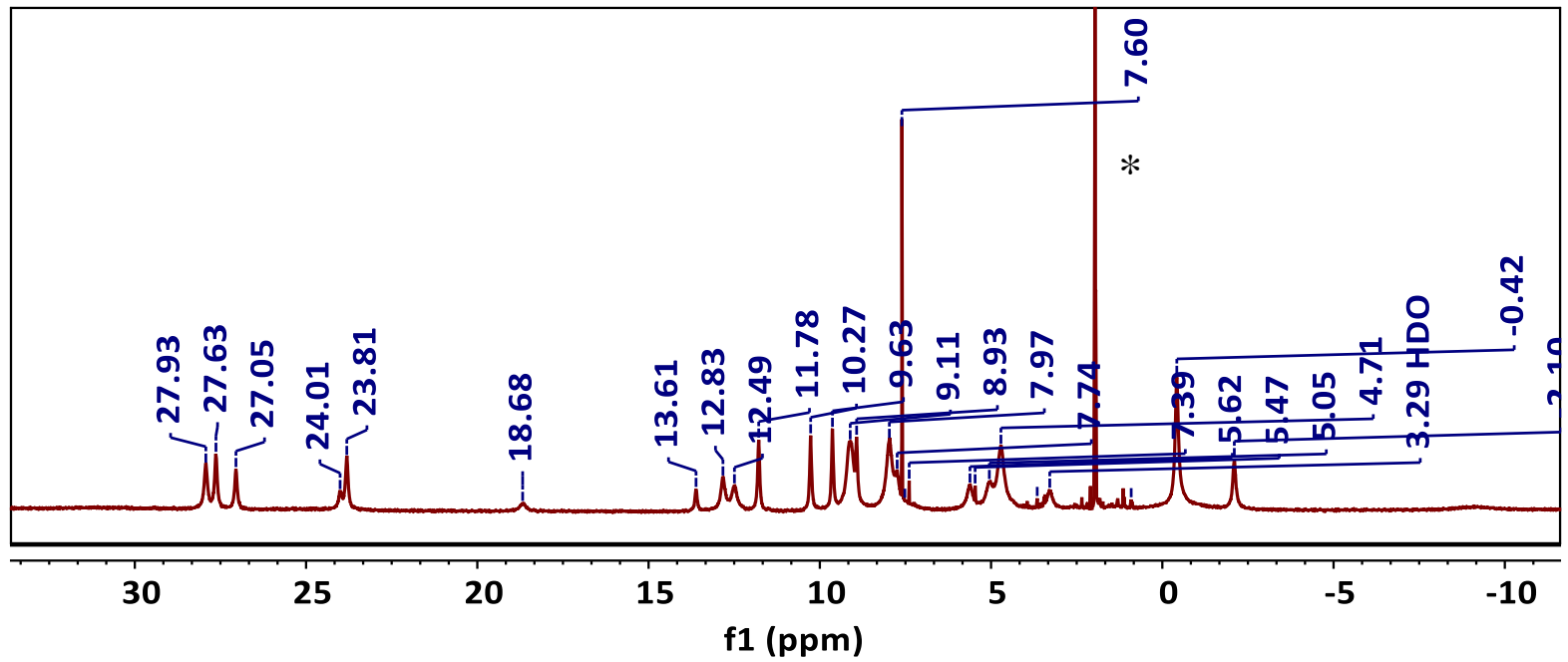

Figure S10: ${ }^{1} \mathrm{H}$ NMR spectrum of $[3][\mathrm{OTf}]_{2}$ in $\mathrm{MeCN}-d_{3}{ }^{*}$



Figure S11: ${ }^{19} \mathrm{~F}\{1 \mathrm{H}\}$ NMR spectrum of $[3][\mathrm{OTf}]_{2}$ in $\mathrm{MeCN}-d_{3}$ 


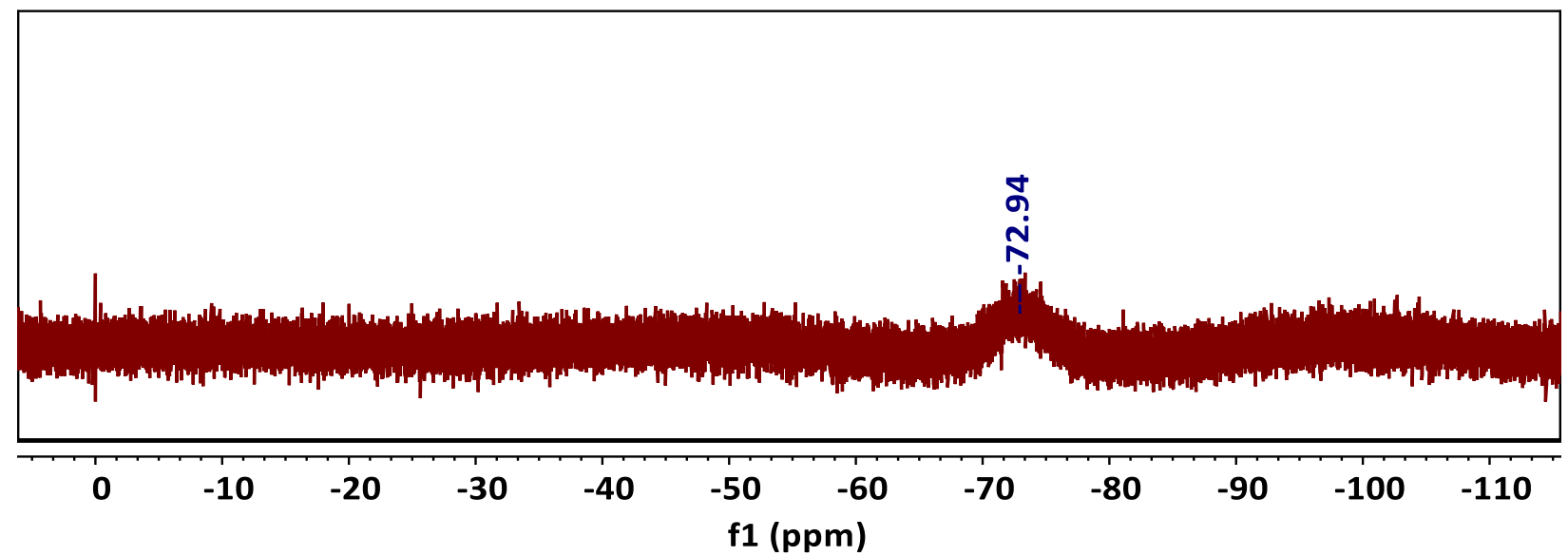

Figure S12: ${ }^{19} \mathrm{~F}\left\{{ }^{1} \mathrm{H}\right\}$ NMR spectrum of $1: 1$ mixture of Tbim and $\mathrm{Fe}(\mathrm{OTf})_{2} \cdot 2 \mathrm{MeCN}$ in $\mathrm{MeCN}-d_{3}$

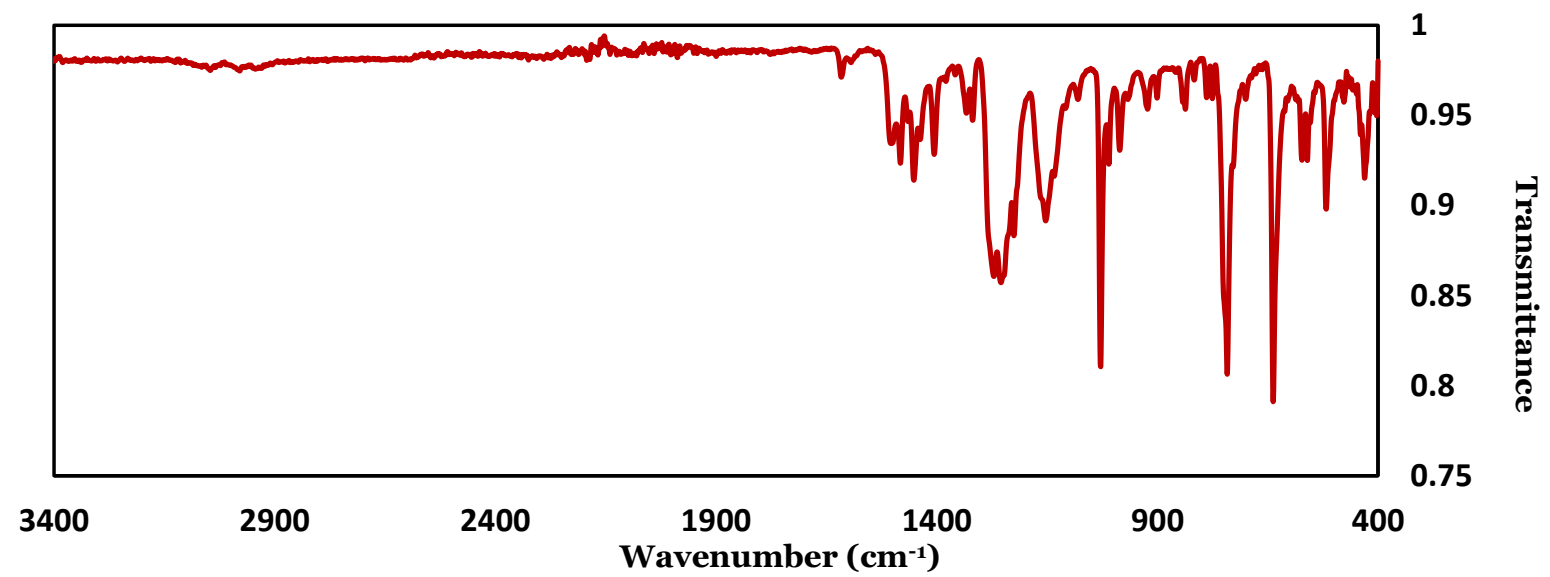

Figure S13: ATR-FTIR spectrum of $[3][\mathrm{OTf}]_{2}$

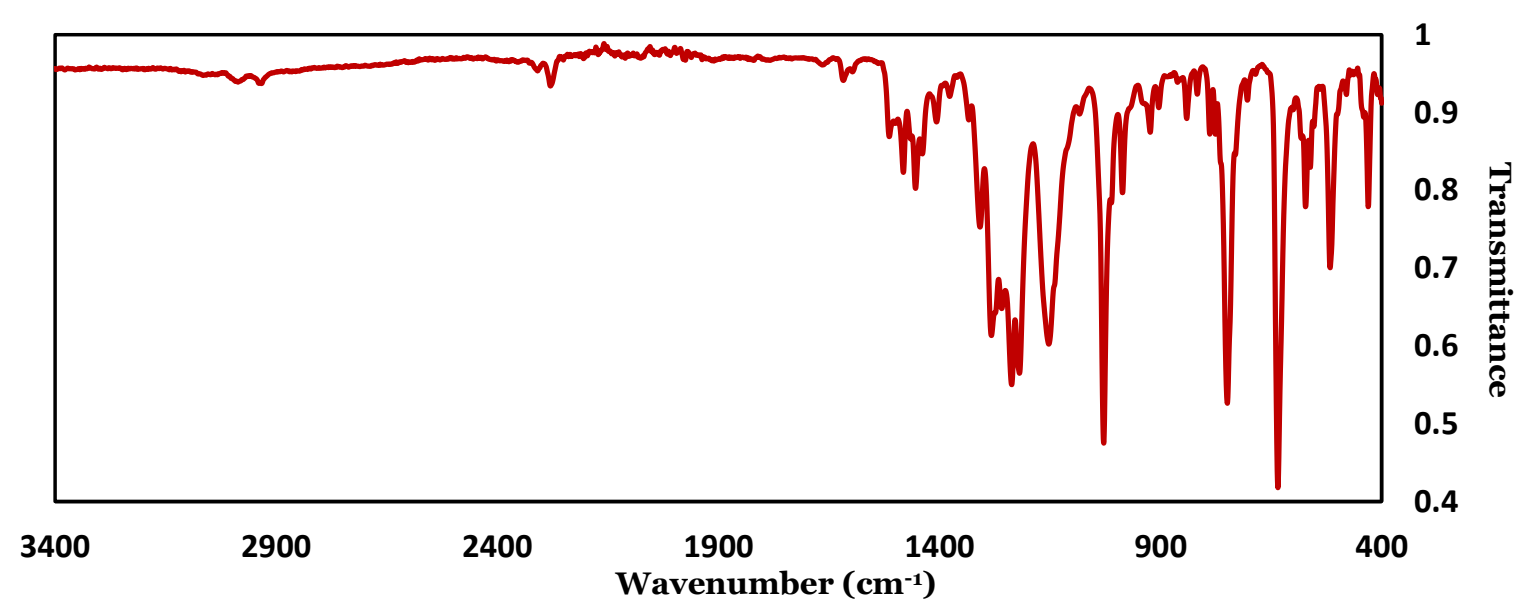

Figure S14: ATR-FTIR spectrum of [4][OTf] with MeCN stretches. 

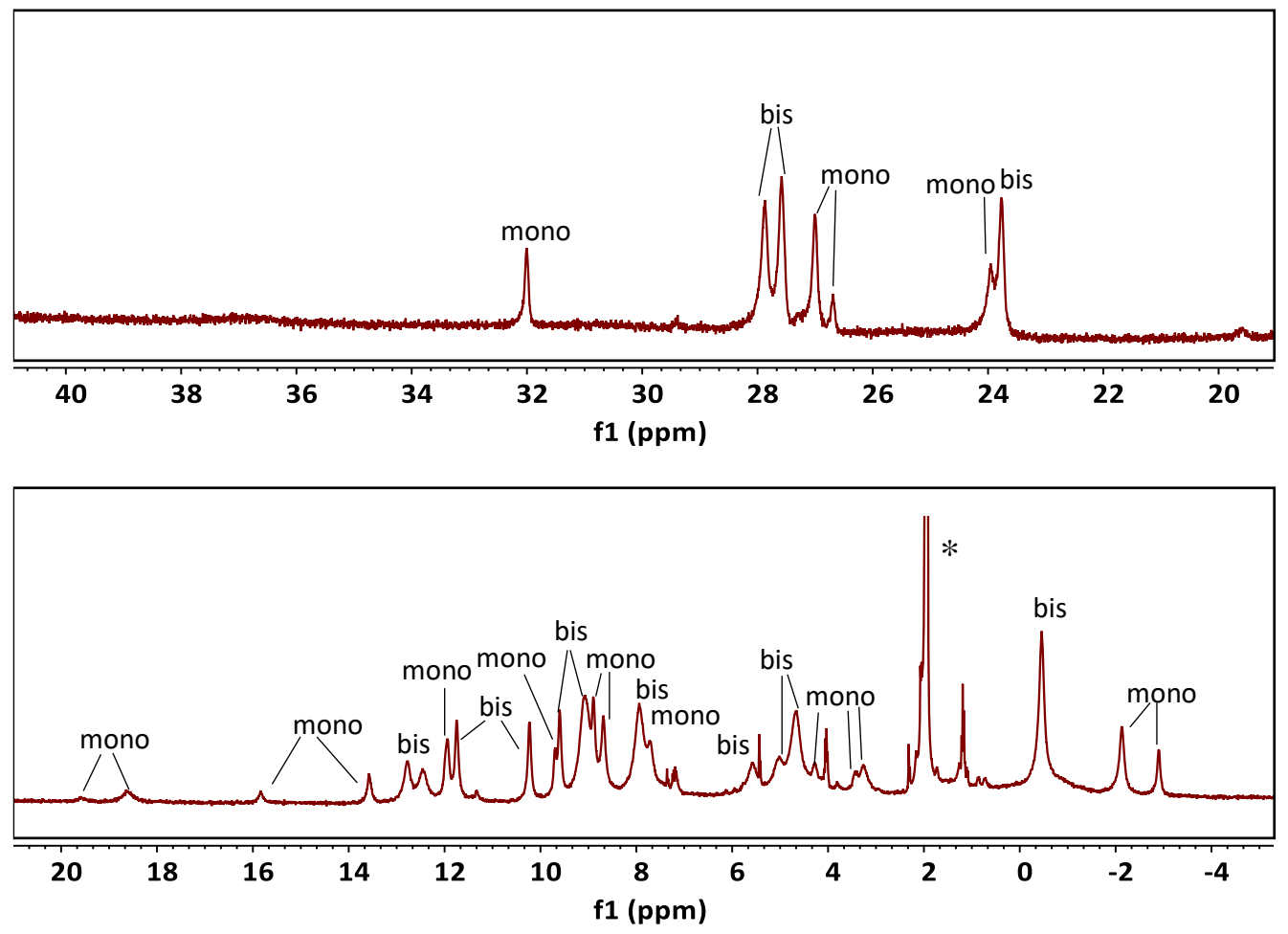

Figure S15: ${ }^{1} \mathrm{H}$ NMR spectrum indicating the presence of $[3][\mathrm{OTf}]_{2}$ (bis) and [4][OTf] (mono) in MeCN- $d_{3}{ }^{*}$

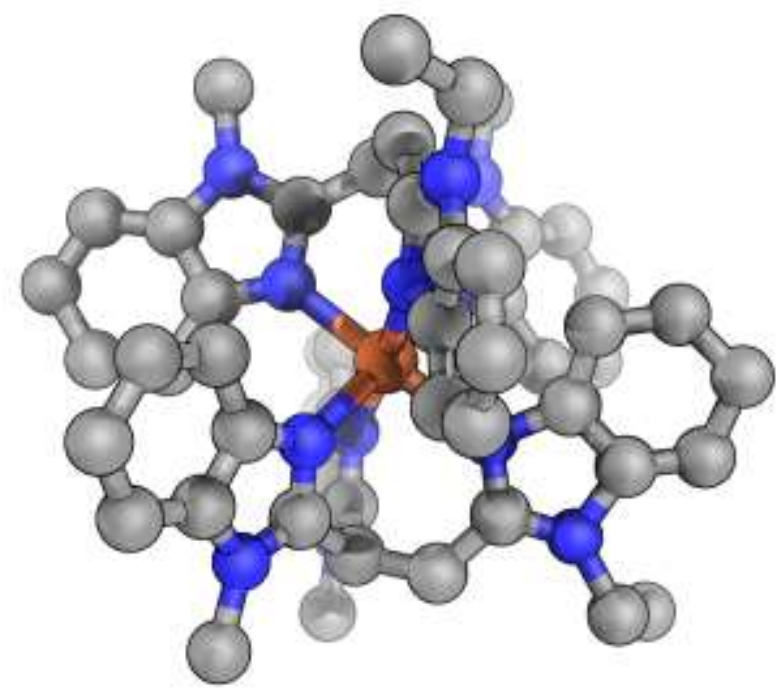

Figures S16: XRD determined connectivity structure of $[3]^{2+}$ (crystallized as the tetraphenylborate salt). Hatoms, counterions, and solvent molecules are not shown. Color scheme: orange $=\mathrm{Fe}$; blue $=\mathrm{N}$; grey $=\mathrm{C}$. 
Procedure for determining optimal ligand-metal ratio for in-situ $[4]^{+}:$Stock solutions of $25 \mathrm{mM}$ Tbim and $\mathrm{Fe}(\mathrm{OTf})_{2} \bullet 2 \mathrm{MeCN}$ (or Fe(OTf) $)_{2} \bullet 6 \mathrm{H}_{2} \mathrm{O}$ ) were prepared in $\mathrm{MeCN}-d_{3}$. The stock solutions of the Tbim and $\mathrm{Fe}^{2+}$ were mixed in different ratios to achieve the desired mole fractions and the total volume was adjusted to $3 \mathrm{~mL}$ using $\mathrm{MeCN}-d_{3}$. The peak at $32 \mathrm{ppm}$, which was identified as a unique peak for [4] ${ }^{+}$, was chosen to construct the plot. The width at half maximum of the $32 \mathrm{ppm}$ peak was measured against the width at half maximum of $\mathrm{CH}_{3}$ peak of toluene (2.29 ppm, internal standard) or the peak height of acetonitrile (1.94 ppm) in the solution to arrive at a relative intensity value at each mole fraction. The plot was constructed by plotting the relative peak height vs. the mole fraction of Tbim/Fe(OTf $)_{2}$. This measurement was replicated four times, each time with the optimal ratio near 3:2 for metal:ligand.

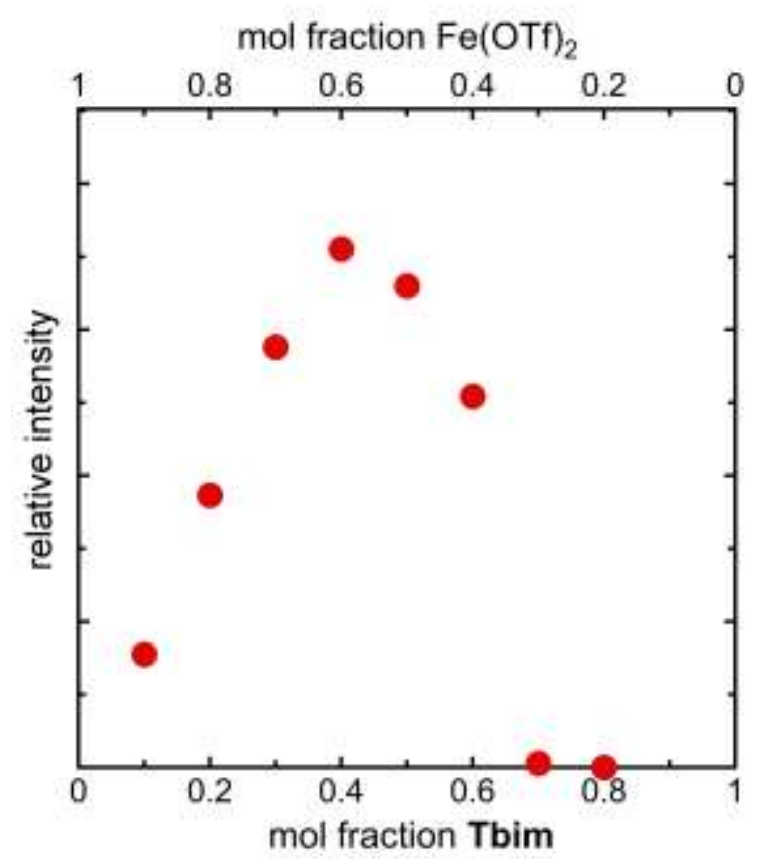

Figure S17: Plot for determining the optimal mole ratio for in situ preparation of [4] using $\mathrm{Fe}(\mathrm{OTf})_{2} \cdot 6 \mathrm{H}_{2} \mathrm{O}$. 
The $\mathrm{p} K_{\mathrm{a}}$ (water) values of 1,2-dimethylbenzimidazole were measured with modifications to the procedures reported by Dardonville et. al. and Benkovic et. al.18,19 Stock solutions of the salts used for buffers were prepared by dissolving the respective salts to get $0.05 \mathrm{M} \mathrm{NaH}_{2} \mathrm{PO}_{4}$, $0.1 \mathrm{M} \mathrm{NaOAc}$, $0.025 \mathrm{M} \mathrm{Na}_{2} \mathrm{~B}_{4} \mathrm{O}_{7}$ and $0.1 \mathrm{M}$ trisodium citrate. $0.1 \mathrm{M} \mathrm{HCl}$ was standardized using $0.1 \mathrm{M} \mathrm{K}_{2} \mathrm{CO}_{3}$ and $0.1 \mathrm{M} \mathrm{NaOH}$ was standardized with the $\mathrm{HCl}$ solution. The buffer solutions were prepared by measuring $50.0 \mathrm{~mL}$ of the appropriate salt solution in a $100.0 \mathrm{~mL}$ volumetric flask and adjusting the $\mathrm{pH}$ using $\mathrm{HCl}$ or $\mathrm{NaOH}$. The ionic strengths of the solutions were calculated using equation 1 and were adjusted to $0.1 \mathrm{M}$ by addition of $\mathrm{KCl}$. The final volume of the buffer solutions was adjusted to $100.0 \mathrm{~mL}$ with distilled water.

$$
I=\frac{1}{2} \sum_{i=1}^{n} c_{i} Z_{i}
$$

equation $S 1$

The stock solution of the 1,2-dimethylbenzimidazole was prepared by dissolving of $45 \mathrm{mg}$ of 1,2dimethylbenzimidazole in $3.0 \mathrm{~mL}$ of DMSO. The solutions for the UV-vis experiment was prepared by diluting $20 \mu \mathrm{L}$ of the stock solution of 1,2-dimethylbenzimidazole to $10.0 \mathrm{~mL}$ with the respective buffer solutions. The absorbance spectra of the solution were measured between $200-400 \mathrm{~nm}$ and the spectra were normalized to 400 $\mathrm{nm}$. The spectral difference at the lowest $\mathrm{pH}$ and each spectrum in different $\mathrm{pH}$ was obtained. The wavelengths that produce the highest positive absorbance and the highest negative absorbance were selected. The total absorbance at a given $\mathrm{pH}$ was calculated by addition of absolute values of the absorbance at the chosen wavelengths and was plotted against the $\mathrm{pH}$. The $\mathrm{p} K_{\mathrm{a}}$ was determined using Origin 2019 by nonlinear regression of equation 2.

$$
\text { Total absorbance }=\frac{\left[\varepsilon_{H A}-\varepsilon_{A}\right]\left[10^{(p H-p K a)}\right]}{1+10^{(p H-p K a)}} \cdot\left[S_{t}\right]
$$

equation $\mathrm{S2}$

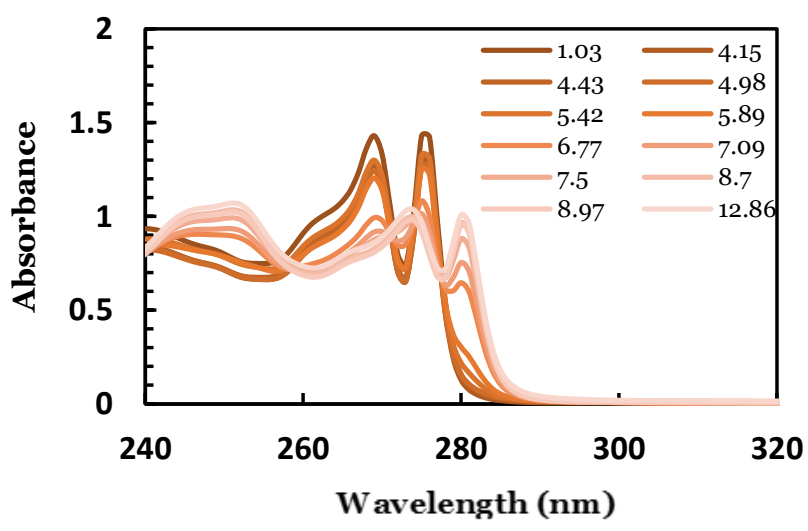

(a)

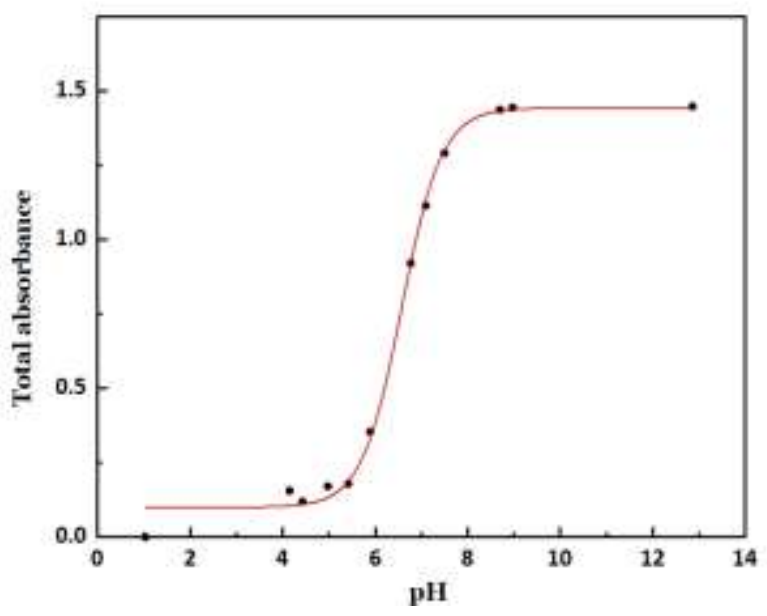

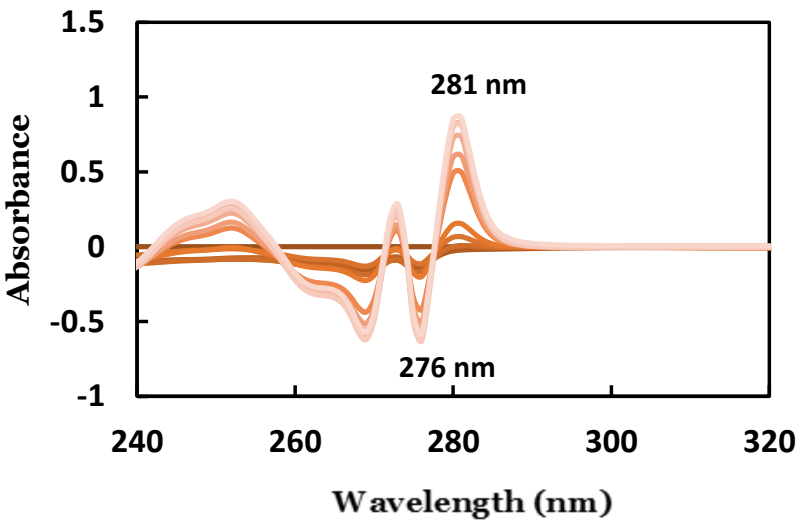

(b)

(c)

Figure 18: (a) UV-vis spectra of 1,2-dimethylbenzimidazole in different $\mathrm{pH}$ buffer solutions (normalized at 400 $\mathrm{nm}$ ), (b) Plot of the spectral difference between different solutions of 1,2-dimethylbenzimidazole in buffer solutions and (c) Total absorbance difference vs $\mathrm{pH}$ graph for determination of $\mathrm{p} K_{\mathrm{a}}$. 
Table S1. $\mathrm{p} K_{\mathrm{a}}\left(\mathrm{H}_{2} \mathrm{O}\right)$ values used for Figure 1 and Figure $\mathrm{S19}^{20}$

\begin{tabular}{c|c|c}
\hline conjugate acid of... & $\mathbf{p} \boldsymbol{K}_{\mathbf{a}}$ & ref \\
\hline pyrrole & -0.38 & 21 \\
\hline pyrazole & 2.49 & 21 \\
\hline pyridine & 5.23 & 21,22 \\
\hline benzimidazole & 5.43 & 23 \\
\hline$N$-methylbenzimidazole & 5.55 & 24 \\
\hline histidine & 6.04 & 21 \\
\hline 2-methylbenzimidazole & 6.19 & 21,24 \\
\hline 1,2-dimethylbenzimidazole & 6.57 & 21,25 \\
\hline imidazole & 6.99 & 25 \\
\hline$N$-methylimidazole & 7.21 & 25 \\
\hline 4-methylimidazole & 7.69 & 21 \\
\hline trimethylamine & 9.80 & 26 \\
\hline H ${ }_{3}$ TACN & 10.44 & 21 \\
\hline triethylamine & 10.75 & 21 \\
\hline diethylamine & 10.84 & 21 \\
\hline guanidine & 13.6 & work (see above) \\
\hline
\end{tabular}

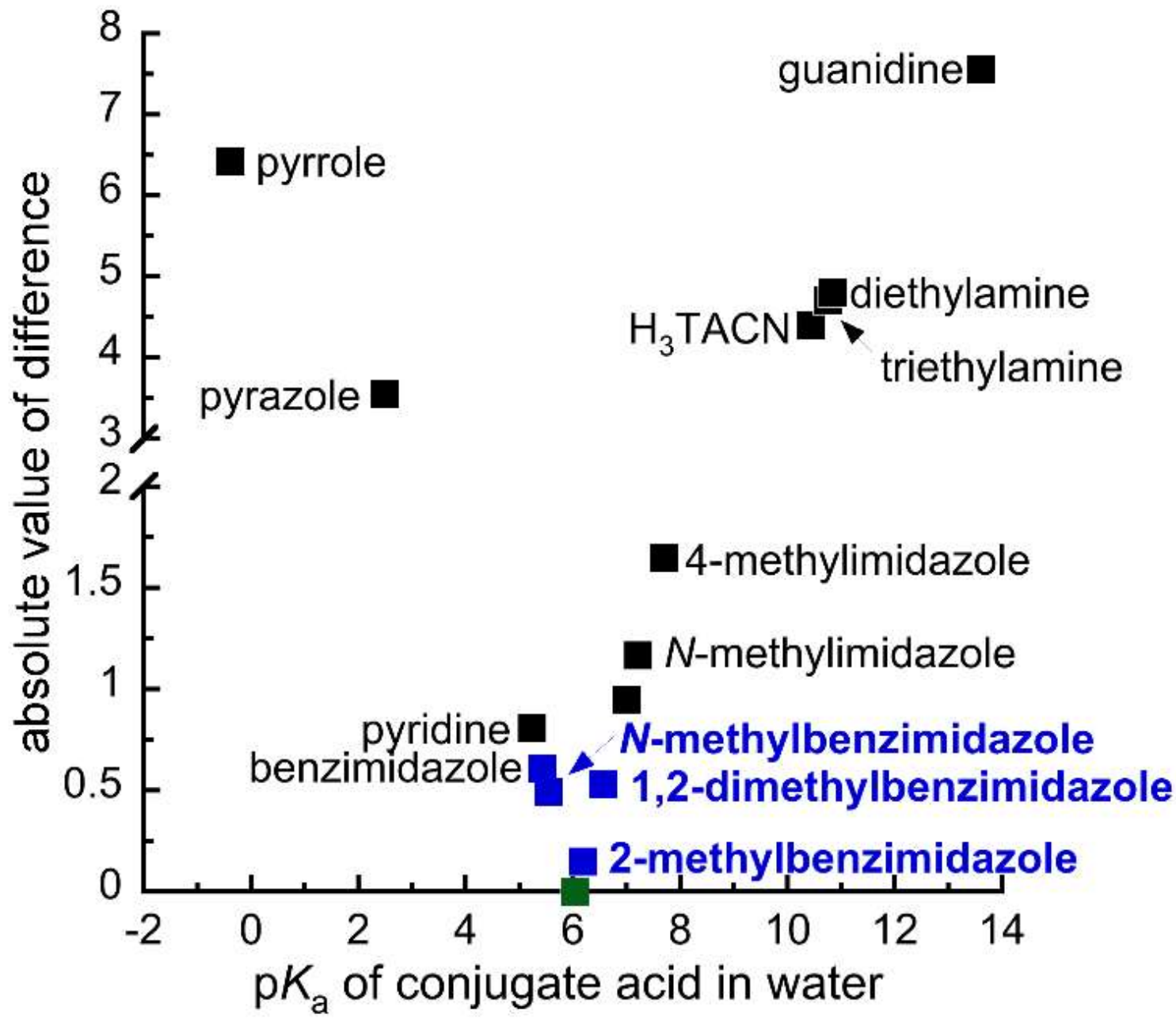

Figure S19: Comparison of ligand conjugate $\operatorname{acid} \mathrm{p} K_{\mathrm{a}}$ to histidine. 


\section{Catalysis}

Li[Phmal] oxidation: Following the literature method, ${ }^{27}$ dry oxygen was bubbled through a reaction mixture with $5 \mathrm{~mol} \%$ catalyst in dry acetonitrile over 1 hour and diethyl 2-hydroxy-2-phenylmalonate (HOPhmal) was obtained as the major product; the biomimetic product the ethyl benzoylformate was only a minor product. An increase in ethyl benzoylformate yield was observed for dropwise addition of the substrate with otherwise identical procedures.

The flasks used for catalysis were assembled inside a nitrogen filled glovebox and reactions were performed on a Schlenk line. Stock solutions of Tbim $(17.8 \mathrm{mg}, 0.0410 \mathrm{mmol}),[\{\mathrm{Tp} *\} \mathrm{Fe}(\mathrm{Phmal})](24.1 \mathrm{mg}$, $0.0410 \mathrm{mmol}), \mathrm{Fe}(\mathrm{OTf})_{2} \cdot 2 \mathrm{MeCN}(67.6 \mathrm{mg}, 0.155 \mathrm{mmol})$ were prepared by dissolving the respective compound in dry acetonitrile and volume was adjusted to $5.0 \mathrm{~mL}$. To produce the catalysts [4][OTf] (mono complex) and [3][OTf $]_{2}$ (bis complex) in situ, stock solutions of the ligand and the metal were mixed in mole ratios deduced from the plot discussed above (Figure S17) prior to the catalysis. The substrate Li[Phmal] (20.0 mg, 0.0826 $\mathrm{mmol}$ ) was dissolved in $5 \mathrm{~mL}$ of dry acetonitrile and loaded to an addition funnel. The respective catalysts were prepared in $3 \mathrm{~mL}$ of dry acetonitrile in a Schlenk flask and stirred for 5 minutes. The setup was taken out from the glovebox and assembled on a Schlenk line. A cannula was inserted for addition of dry oxygen (oxygen was dried by flowing gas through a Drierite column followed by chilled glass tubing, $-78^{\circ} \mathrm{C}$ ). The cannula was submerged and oxygen was bubbled through the solution. Immediately after oxygen bubbling was initiated, substrate was gradually added over a period of 15 minutes via a drop funnel. Note that addition of substrate was initiated just before oxygen bubbling. After complete addition of substrate, the funnel was washed with $2 \mathrm{~mL}$ of dry acetonitrile and was subsequently added dropwise to the same reaction mixture. Oxygen was bubbled for a total of 1 hour after which $0.5 \mathrm{~mL}$ of $3 \mathrm{M} \mathrm{HCl}$ was added. The total volume of the solution was adjusted to $10 \mathrm{~mL}$ in a volumetric flask with acetonitrile. $200 \mu \mathrm{L}$ of this solution was treated with a known amount internal standard (anthracene dissolved in DCM) and then diluted to $5 \mathrm{~mL}$ with DCM and directly analyzed using GC-MS. Yields were determined using calibration curves prepared from independently synthesized products and reagents with anthracene as the internal standard.

Table S2: Results from catalytic aerobic oxidation of lithium diethyl 2-phenylmalonate (Li[Phmal]) (dropwise addition of substrate).

\begin{tabular}{|c|c|c|c|c|c|c|}
\hline \multirow[b]{2}{*}{ Catalyst } & \multicolumn{2}{|c|}{ HPhmal (\%) } & \multicolumn{2}{|c|}{ Et-benzoylformate (\%) } & \multicolumn{2}{|c|}{ HOPhmal (\%) } \\
\hline & run 1 & run 2 & run 1 & run 2 & run 1 & run 2 \\
\hline Fe/Tbim (3:2) & $\mathrm{O}$ & $\mathrm{O}$ & 18 & 25 & 50 & 31 \\
\hline Fe/Tbim (1:4) & o & O & 15 & 19 & 61 & 40 \\
\hline$\left[\left\{\mathrm{Tp}^{*}\right\} \mathrm{Fe}(\mathrm{Phmal})\right]$ & $\mathrm{O}$ & $\mathrm{O}$ & 20 & 21 & 47 & 42 \\
\hline Fe/no ligand & o & o & 14 & 18 & 42 & 40 \\
\hline $\mathbf{F e} / \mathbf{P h}_{2} \mathbf{N H}$ & 54 & 68 & $\mathrm{O}$ & $\mathrm{O}$ & 13 & 20 \\
\hline no iron or ligand & 88 & 65 & o & o & 5 & 3 \\
\hline
\end{tabular}


Sodium thiocresol oxidation: The flasks used for catalysis were assembled inside a nitrogen filled glovebox and reactions were performed on a Schlenk line. Stock solutions of Tbim (29.7 mg, $0.0684 \mathrm{mmol}), \mathrm{K}\left[\mathbf{T p} \mathbf{p}^{*}\right]$ (11.5 mg, $0.0684 \mathrm{mmol}), \mathrm{Fe}(\mathrm{OTf})_{2} \cdot 2 \mathrm{MeCN}(29.8 \mathrm{mg}, 0.0684 \mathrm{mmol})$ were prepared by dissolving the respective compound in dry acetonitrile and volume adjusted to $5.0 \mathrm{~mL}$. To produce the catalysts [4][OTf] (mono complex) and [3][OTf $]_{2}$ (bis complex) in situ, stock solutions of the ligand and the metal was mixed in mole ratios deduced from the plot prior to the catalysis. Sodium thiocresol $(20.0 \mathrm{mg}, 0.137 \mathrm{mmol})$ was added to the solution of catalyst and charged with a stir bar in a Schlenk flask and total volume was adjusted to $5 \mathrm{~mL}$ with dry acetonitrile. The Schlenk flask was taken out of the glovebox and dry oxygen was added to the headspace of the reaction mixture through a cannula (oxygen was dried by flowing gas through Drierite column followed by $-78{ }^{\circ} \mathrm{C}$ chilled glass tubing). The reaction was stirred for 1 hour with dry oxygen, after which addition of oxygen ceased and the solution was acidified with $1 \mathrm{~mL}$ of $3 \mathrm{M} \mathrm{HCl}$ to protonate the sodium salts. The solution stirred for another 30 minutes and then the volatiles were removed under vacuum. The residual solid was dissolved in DMSO- $d_{6}$ and the yields of the products were determined using ${ }^{1} \mathrm{H}$ NMR spectroscopy. To get a relative conversion, $100 \%$ conversion of the substrate was assumed and the yields were calculated using the integration of the methyl peaks (I) of the expected products via the following equation.

$$
\% \text { yield }=\frac{I_{\text {product }}}{I_{\text {total }}} \times 100 \%
$$

equation $S_{3}$

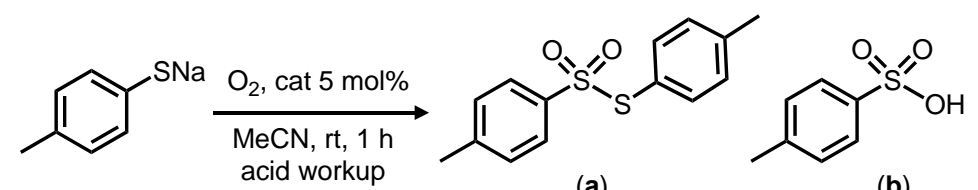

(a)<smiles>Cc1ccc(S(=O)O)cc1</smiles>

(c)<smiles>Cc1ccc(SSc2ccc(C)cc2)cc1</smiles>

(d)

Table S3: Results from catalytic aerobic oxidation of sodium thiocresol.

\begin{tabular}{l|cc|cc|cc|cc}
\hline \multirow{2}{*}{ Catalyst } & \multicolumn{2}{|c|}{ a (\%) } & \multicolumn{2}{|c|}{ b (\%) } & \multicolumn{2}{c|}{ c (\%) } & \multicolumn{2}{c}{ d (\%) } \\
\cline { 2 - 9 } & run 1 & run 2 & run 1 & run 2 & run 1 & run 2 & run 1 & run 2 \\
\hline Fe/Tbim (3:2) & 12 & 21 & 0 & 0 & 53 & 55 & 35 & 24 \\
Fe/Tbim (1:4) & 4 & 6 & 13 & 7 & 63 & 70 & 20 & 16 \\
Fe/Tp* & 18 & 0 & 5 & 0 & 72 & 67 & 5 & 33 \\
Fe/no ligand & 12 & 18 & 11 & 0 & 63 & 59 & 15 & 4 \\
no iron or ligand & 5 & 3 & 34 & 5 & 54 & 88 & 6 & 4 \\
\hline
\end{tabular}




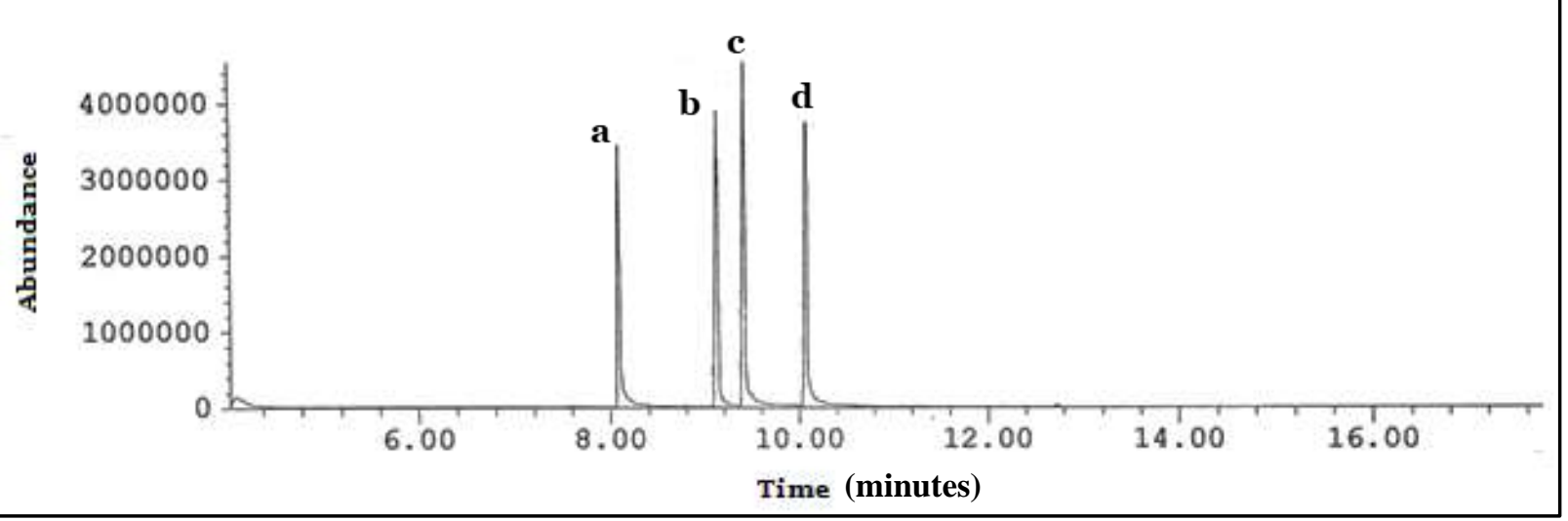

Figure S20: GC trace for HPhmal and its oxidation products prepared independently. a: ethyl benzoylformate, b: HPhmal, c: HOPhmal and d: anthracene internal standard.

Ethyl benzoylformate: ${ }^{1} \mathrm{H}$ NMR (Chloroform- $d$, $\left.300 \mathrm{MHz}\right): \delta 1.39(\mathrm{t}, 2 \mathrm{H}), 4.41(\mathrm{q}, 2 \mathrm{H}), 7.48(\mathrm{tt}, 2 \mathrm{H}$, aromatic), 7.63 (tt, $1 \mathrm{H}$, aromatic), 7.97 (d, $2 \mathrm{H}$, aromatic). ${ }^{13} \mathrm{C}$ NMR (Chloroform- $d, 75 \mathrm{MHz}$ ): $\delta$ 14.26, $62.47,129.03,130.17,132.63,135.03,163.96,186.56$.



Figure S21: ${ }^{1} \mathrm{H}$ NMR spectrum of ethyl benzoylformate in chloroform- $d^{*}$

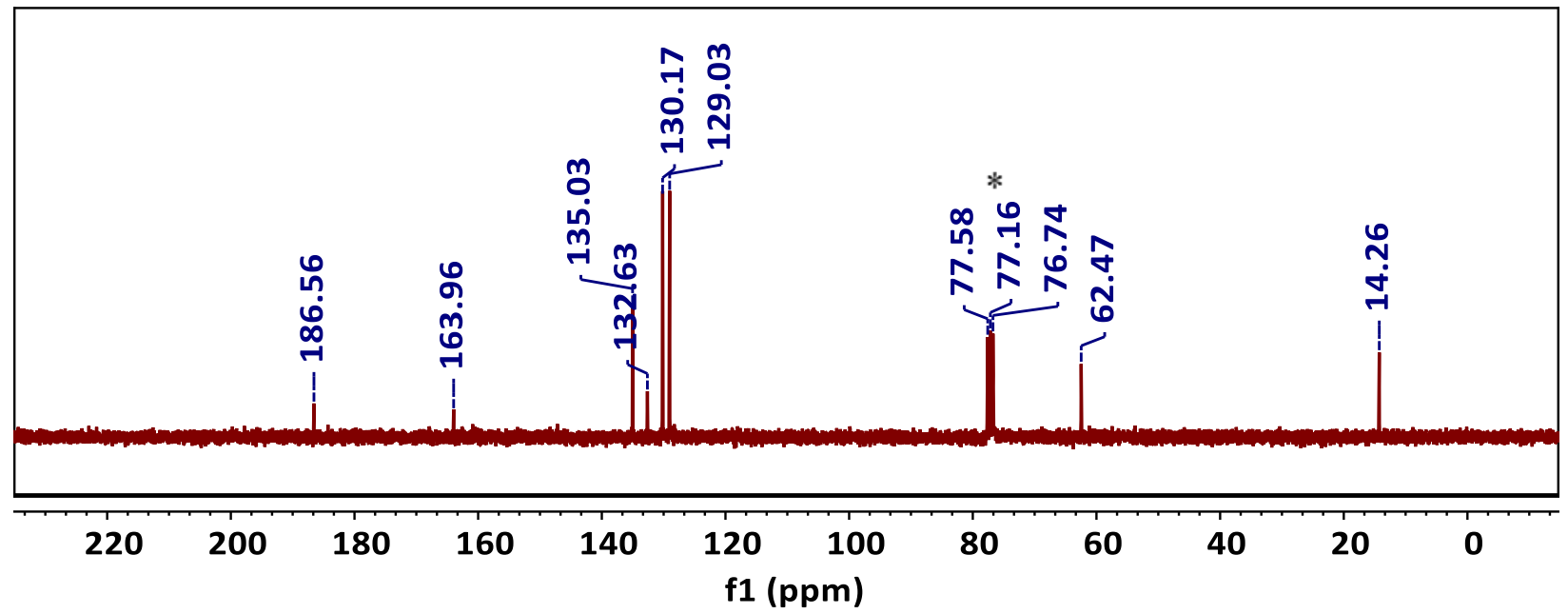

Figure S22: ${ }^{13} \mathrm{C}$ NMR spectrum of ethyl benzoylformate in chloroform- $d^{*}$ 
Diethyl 2-hydroxy-2-phenylmalonate (HOPhmal): Diethyl 2-hydroxy-2-phenylmalonate (HOPhmal) was prepared according to the following procedure: LiPhmal (32 mg, $0.132 \mathrm{mmol})$ was stirred with $5 \mathrm{~mL}$ of dry acetonitrile in the presence of air for 16 hours. The solution was treated with $0.5 \mathrm{~mL}$ of $3 \mathrm{M} \mathrm{HCl}$ and the solvent was removed under vacuum. The aqueous layer was extracted with $3 \times 2 \mathrm{~mL}$ of dichloromethane and the solvent evaporated to obtain the product as a colorless clear liquid (23 mg, 70\% yield). ${ }^{1} \mathrm{H}$ NMR data matches with the literature reported values. ${ }^{28}{ }^{1} \mathrm{H}$ NMR (Chloroform- $d$, $\left.300 \mathrm{MHz}\right): \delta 1.28\left(\mathrm{t}, 6 \mathrm{H}, \mathrm{CH}_{3}\right), 4.30\left(\mathrm{q}, 4 \mathrm{H}, \mathrm{CH}_{2}\right), 4.40(\mathrm{br}$, $1 \mathrm{H}, \mathrm{OH}$ ), 7.36 (m, $3 \mathrm{H}$, aromatic), 7.65 (d, $2 \mathrm{H}$, aromatic). ${ }^{13 \mathrm{C} N M R}$ (Chloroform- $d, 75 \mathrm{MHz}$ ): $\delta$ 169.9, 136.0, 128.6, 128.0, 126.7, 80.0, 63.0, 14.0.
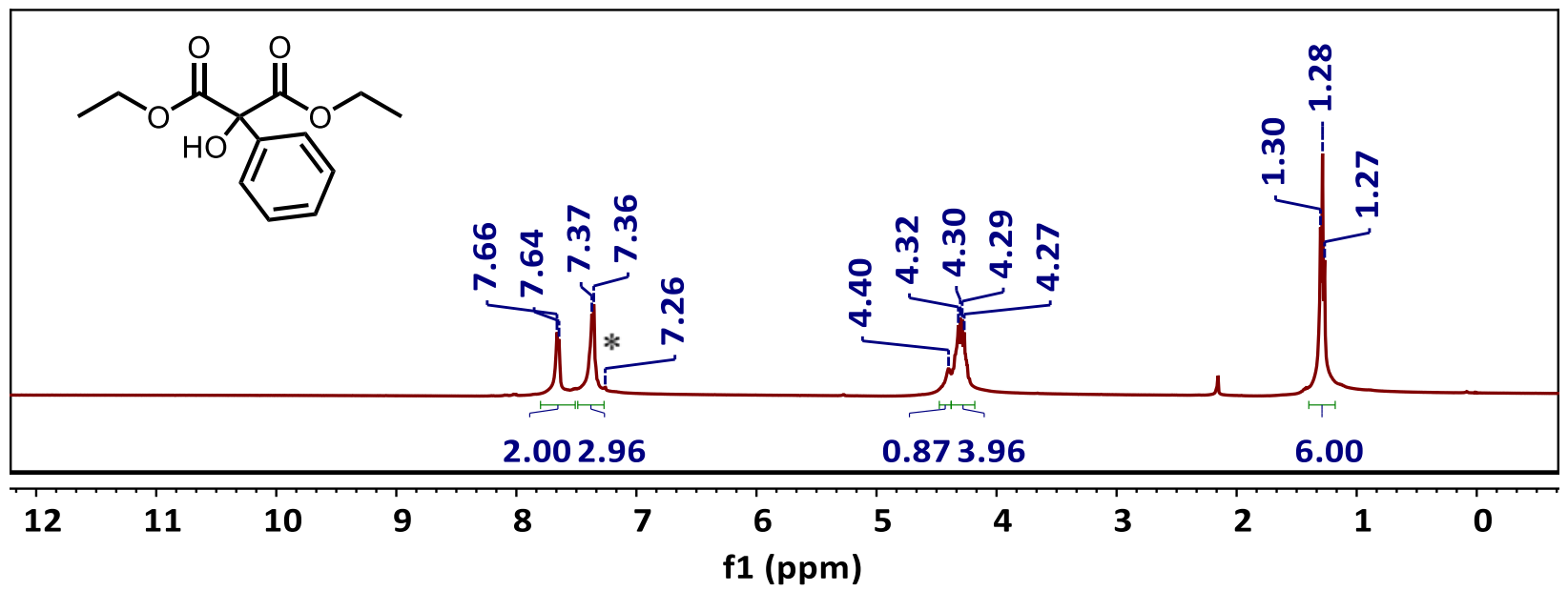

Figure S23: ${ }^{1} \mathrm{H}$ NMR spectrum of $\mathrm{HOPhmal}$ in chloroform- $d^{*}$

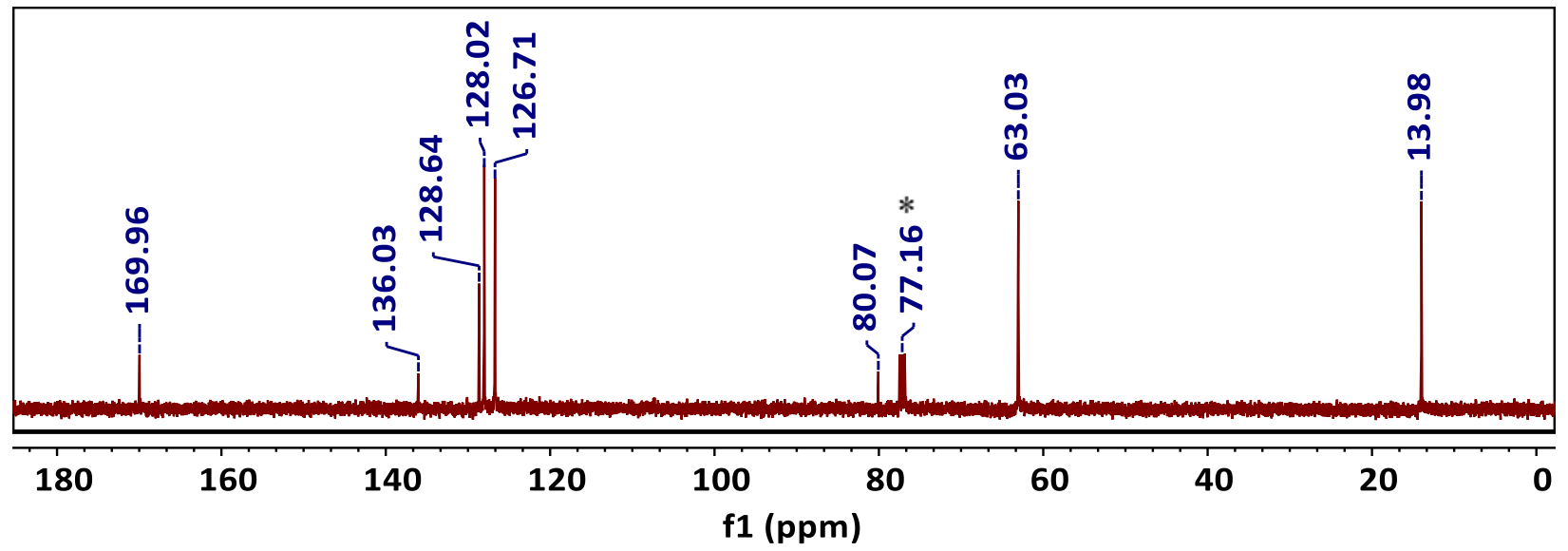

Figure S24: ${ }^{13} \mathrm{C}$ NMR spectrum of HOPhmal in chloroform- $d^{*}$

p-toluenesulfinic acid: ${ }^{1} \mathrm{H}$ NMR $\left(D M S O-d_{6}, 300 \mathrm{MHz}\right): \delta 2.35(\mathrm{~s}, 3 \mathrm{H}), 7.38(\mathrm{~d}, 2 \mathrm{H}$, aromatic), $7.54(\mathrm{~d}, 2 \mathrm{H}$, aromatic)

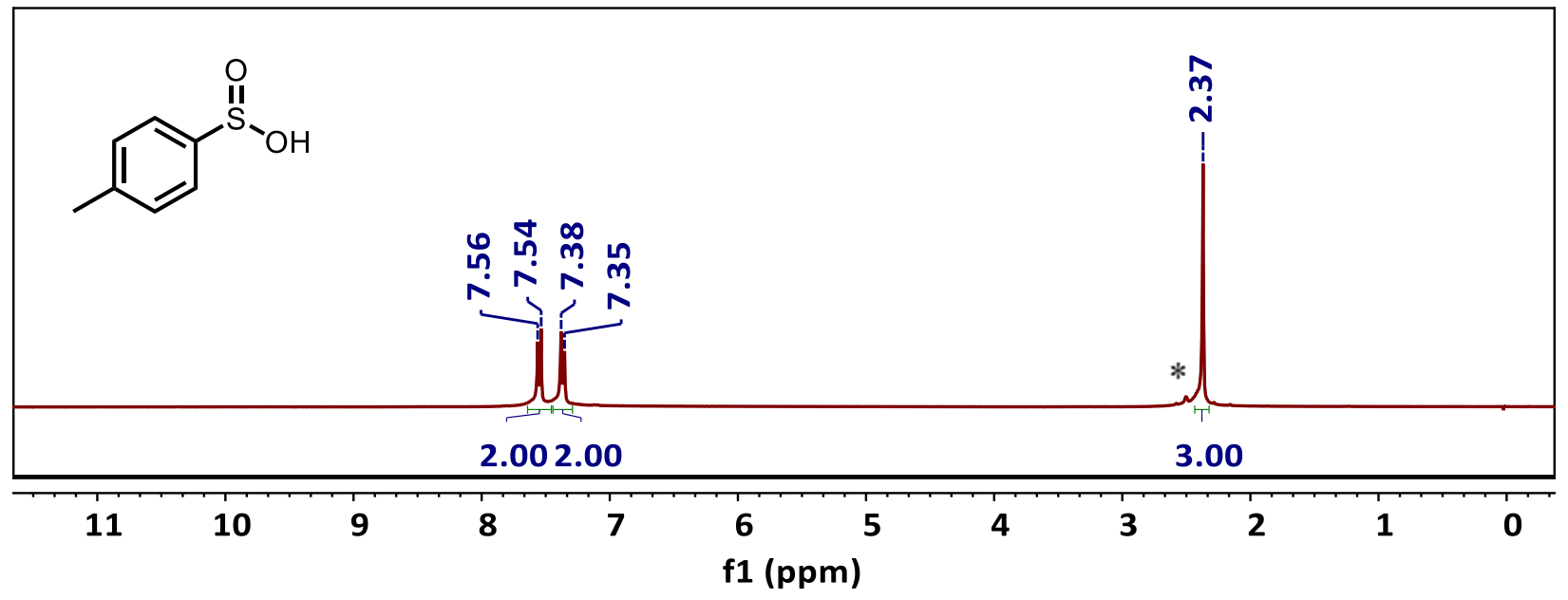


Figure S25: ${ }^{1} \mathrm{H}$ NMR spectrum of $p$-toluenesulfinic acid in DMSO- $d_{6}{ }^{*}$

1,2-di-p-tolyldisulfane: ${ }^{1} \mathrm{H}$ NMR (DMSO- $\left.d_{6}, 300 \mathrm{MHz}\right): \delta 2.28(\mathrm{~s}, 3 \mathrm{H}), 7.20(\mathrm{~d}, 4 \mathrm{H}$, aromatic), $7.38(\mathrm{~d}, 4 \mathrm{H}$, aromatic)

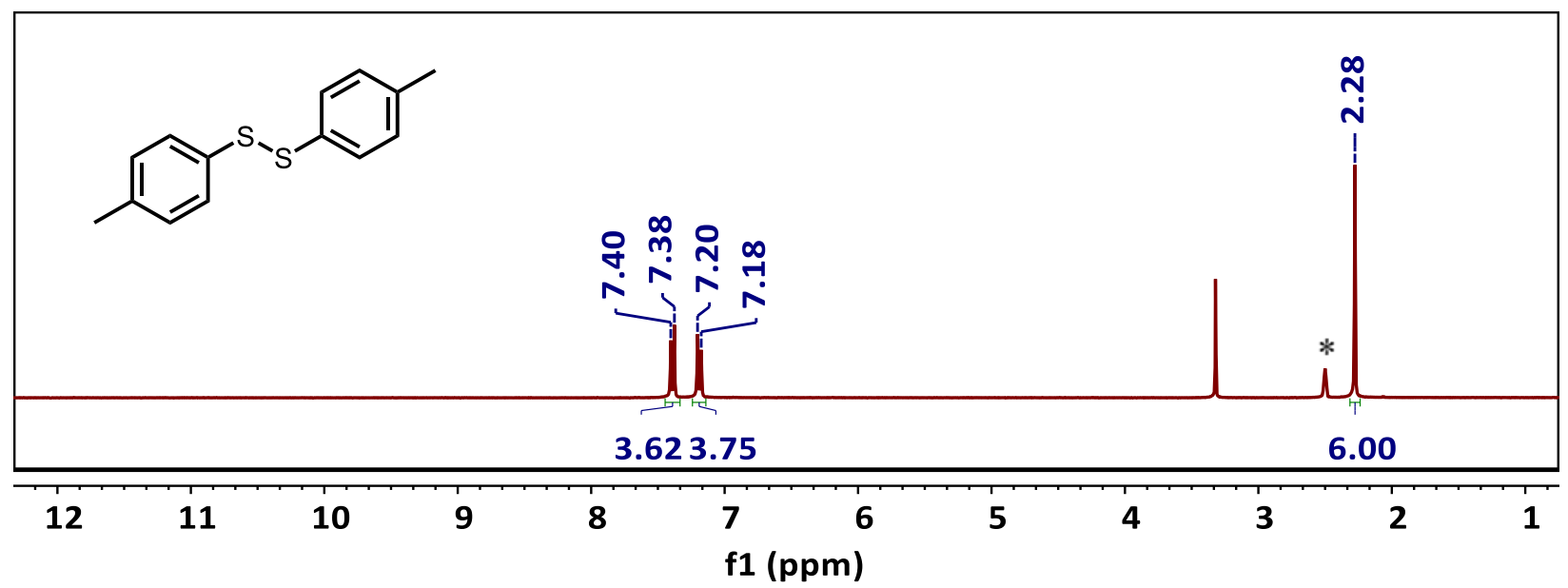

Figure S26: ${ }^{1} \mathrm{H}$ NMR spectrum of 1,2-di-p-tolyldisulfane in DMSO- $d_{6}{ }^{*}$

p-toluenesulfonic acid: ${ }^{1} \mathrm{H}$ NMR (DMSO- $\left.d_{6}, 300 \mathrm{MHz}\right): \delta 2.29(\mathrm{~s}, 3 \mathrm{H}), 7.14(\mathrm{~d}, 4 \mathrm{H}$, aromatic), $7.48(\mathrm{~d}, 4 \mathrm{H}$, aromatic)



Figure S27: ${ }^{1} \mathrm{H}$ NMR spectrum of $p$-toluenesulfonic acid in DMSO- $d_{6}{ }^{*}$

S-(4-methylphenyl) 4-methylbenzenesulfonothioate: ${ }^{1} \mathrm{H}$ NMR (DMSO- $d_{6}, 300 \mathrm{MHz}$ ): $\delta 2.32$ (s, $3 \mathrm{H}$ ), $2.37(\mathrm{~s}, 3 \mathrm{H}), 7.20$ (q, $4 \mathrm{H}$, aromatic), 7.41 (q, 4H, aromatic)

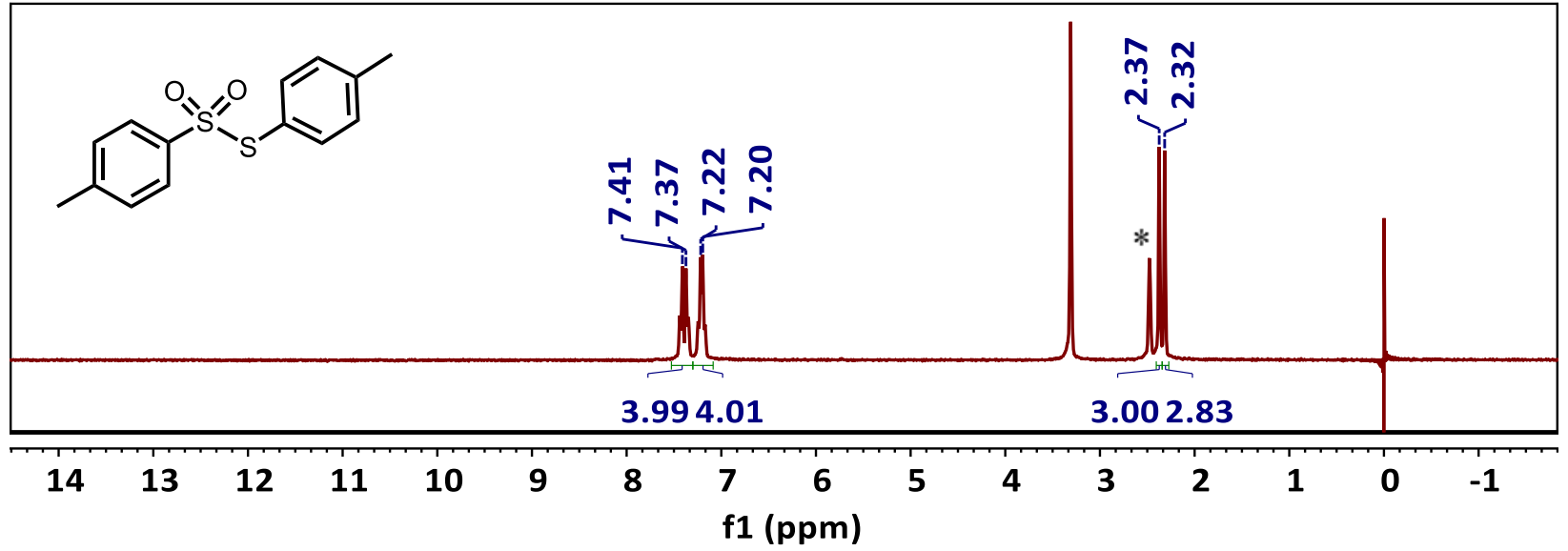

Figure S28: ${ }^{1} \mathrm{H}$ NMR spectrum of S-(4-methylphenyl) 4 -methylbenzenesulfonothioate in DMSO- $d_{6}{ }^{*}$ 
Determination of Schlenk equilibrium from DFT: The Gibb's free energy changes at standard conditions in gas phase $\left(\Delta G_{\mathrm{gas}}\right)$ and in $\mathrm{MeCN}\left(\Delta G_{\mathrm{MeCN}}\right)$ were calculated for the following reactions;

$$
\begin{aligned}
& {\left[\mathrm{Fe}(\text { Tbim })_{2}\right][\mathrm{OTf}]_{2}+2 \mathrm{MeCN} \rightleftharpoons\left[\mathrm{Fe}(\text { Tbim })(\mathrm{MeCN})_{2}(\mathrm{OTf})\right][\mathrm{OTf}]+\text { Tbim } \quad \text { Rxn. } 1} \\
& {\left[\mathrm{Fe}(\text { Tbim })_{2}\right][\mathrm{OTf}]_{2}+\text { trans }-\left[\mathrm{Fe}(\mathrm{MeCN})_{4}(\mathrm{OTf})_{2}\right] \rightleftharpoons 2\left[\mathrm{Fe}(\mathrm{Tbim})(\mathrm{MeCN})_{2}(\mathrm{OTf})\right][\mathrm{OTf}] \quad \text { Rxn. } 2} \\
& \text { trans }-\left[\mathrm{Fe}(\mathrm{MeCN})_{4}(\mathrm{OTf})_{2}\right]+\text { Tbim } \rightleftharpoons\left[\mathrm{Fe}(\text { Tbim })(\mathrm{MeCN})_{2}(\mathrm{OTf})\right][\mathrm{OTf}]+2 \mathrm{MeCN} \quad \text { Rxn. } 3 \\
& \text { trans }-\left[\mathrm{Fe}(\mathrm{MeCN})_{4}(\mathrm{OTf})_{2}\right]+2 \text { Tbim } \rightleftharpoons\left[\mathrm{Fe}(\text { Tbim })_{2}\right][\mathrm{OTf}]_{2}+4 \mathrm{MeCN} \quad \text { Rxn. } 4
\end{aligned}
$$

Table 4: DFT computed Gibbs's free energies for Schlenk equilibrium

\begin{tabular}{c|c|c}
\hline Reaction & $\Delta G_{\text {gas }}(\mathrm{kcal} / \mathbf{m o l})$ & $\Delta G_{\text {MeCN }}(\mathbf{k c a l} / \mathbf{m o l})$ \\
\hline Rxn. 1 & -96.75 & +32.31 \\
Rxn. 2 & -41.91 & +3.163 \\
Rxn. 3 & +54.84 & -29.14 \\
Rxn. 4 & +151.6 & -61.45 \\
\hline
\end{tabular}

\section{References}

1. Hagen, K. S. Iron(II) Triflate Salts as Convenient Substitutes for Perchlorate Salts:Crystal Structures of $\left[\mathrm{Fe}\left(\mathrm{H}_{2} \mathrm{O}\right)_{6}\right]\left(\mathrm{CF}_{3} \mathrm{SO}_{3}\right)_{2}$ and $\mathrm{Fe}(\mathrm{MeCN})_{4}\left(\mathrm{CF}_{3} \mathrm{SO}_{3}\right)_{2}$. Inorg. Chem. 2ooo, 39, 5867-5869.

2. lgafi, S.; Field, L. D.; Messerle, B. A.; Turner, P.; Hambley, T. W. Rhodium Complexes Containing Bidentate Imidazolyl Ligands: Synthesis and Structure. J. Organomet. Chem. 1999, 588, 69-77.

3. Sahay, I. I.; Ghalsasi, P. S. Synthesis of New 1,2,3-Triazole Linked Benzimidazole Molecules as AntiProliferative Agents. Synth. Commun. 2017, 47, 825-834.

4. Siewert, I.; Limberg, C. A Trispyrazolylborato iron malonato complex as a functional model for the acetylacetone dioxygenase. Angew. Chem. Int. Ed. 2008, 47, 7953-7956.

5. Yamada, T.; Kuwata, M.; Takakura, R.; Monguchi, Y.; Sajiki, H.; Sawama, Y. Organocatalytic Nitroaldol Reaction Associated with Deuterium-Labeling. Adv. Synth. Catal. 2018, 36o, 637-641.

6. Vibert, F.; Marque, S. R. A.; Bloch, E.; Queyroy, S.; Bertrand, M. P.; Gastaldi, S.; Besson, E. Design of WallFunctionalized Hybrid Silicas Containing Diazene Radical Precursors. EPR Investigation of Their Photolysis and Thermolysis. J. Phys. Chem. C. 2015, 119, 5434-5439.

7. Reichardt, C.; Erfurt, H. P.; Harms, K.; Schäfer, G. Syntheses, Absolute Configurations, and UV/Vis Spectroscopic Properties of New Chiral Tri- and Pentamethinium Streptocyanine Dyes with 4Aminophenyl 4-Methylphenyl Sulfoxide Endgroups. European J. Org. Chem. 2002, 3, 439-452.

8. Zhao, X.; Liu, T. X.; Zhang, G. Synthesis of Thiosulfonates via CuI-Catalyzed Reductive Coupling of Arenesulfonyl Chlorides Using $\mathrm{Na}_{2} \mathrm{SO}_{3}$ or $\mathrm{NaHSO}_{3}$ as Reductants. Asian J. Org. Chem. 2017, 6, 677-681.

9. $\quad$ Kirihara, M.; Asai, Y.; Ogawa, S.; Noguchi, T.; Hatano, A.; Hirai, Y. A Mild and Environmentally Benign Oxidation of Thiols to Disulfides. Synthesis. 2007, 21, 3286-3289.

10. CrysAlisPro; Rigaku OD, The Woodlands, TX, 2015.

11. Sheldrick, G. M., SHELXT - Integrated Space-Group and Crystal-Structure Determination. Acta Cryst. 2015, $A 71,3-8$.

12. Sheldrick, G.M. A Short History of SHELX. Acta Cryst. 2008, A64, 112-122.

13. Müller, P. Practical Suggestions for Better Crystal Structures. Crystallogr. Rev. 2009, 15, 57-83.

14. (a) Neese, F. Wiley Interdiscip. Rev. Comput. Mol. Sci. 2012, 2, 73. (b) Neese, F. Wiley Interdiscip. Rev. Comput. Mol. Sci. 2018, 8, 4 .

15. (a) Grimme, S.; Ehrlich, S.; Goerigk, L. J. Comput. Chem. 2011, 32, 1456. (b) Grimme, S.; Antony, J.; Ehrlich, S.; Krieg, H. J. Chem. Phys. 2010, 132, 154104.

16. (a) Johnson E. R.; Becke, A. D. J. Chem. Phys. 2005, 123, 024101. (b) Becke, A. D.; Johnson, E. R. J. Chem. Phys. 2005, 123, 154101. (c) Johnson, E. R.; Becke, A. D. J. Chem. Phys. 2oo6, 124, 174104.

17. Weigend, F.; Ahlrichs, R. Phys. Chem. Chem. Phys. 2005, 7, 3297.

18. Martínez, C. H. R.; Dardonville, C. Spectroscopy Using 96-Well Microtiter Plates. ACS Med. Chem. Lett. 2013, 4, 142-145.

19. Tomsho, J. W.; Pal, A.; Hall, D. G.; Benkovic, S. J. Ring Structure and Aromatic Substituent Effects on the $\mathrm{p} K_{\text {a. }}$ ACS Med. Chem. Lett. 2012, 3, 48-52.

20. Moser, A.; Range, K.; York, D. M. Accurate Proton Affinity and Gas-Phase Basicity Values for Molecules Important in Biocatalysis. J. Phys. Chem. B. 2010, 114, 13911-13921. 
21. Haynes, W. M. CRC Handbook of Chemistry and Physics- Dissociation Constants of Organic Acids and Bases, 2010-2011. Josep A. DiVerdi-University of Colorado https://sites.chem.colostate.edu/diverdi/all courses/CRC\%20reference\%20data/dissociation\%20c onstants\%200f\%200rganic\%20acids\%20and\%20bases.pdf (accessed on March 5, 2020).

22. Kyrgowski, T. M.; Szatylowicz, H.; Zachara, J. E. How H-bonding Modifies Molecular Structure and $\pi$-Electron Delocalization in the Ring of Pyridine/Pyridinium Derivatives Involved in $\mathrm{H}$-Bond Complexation. J. Org. Chem. 2005, 70, 8859-8865.

23. Walba, H. \& Isensee, R. W. Acidity constants of some arylimidazoles and their cations. J. Org. Chem. 1961, 26, 2789-2791.

24. Jerez, G.; Kaufman, G.; Prystai, M.; Schenkeveld, S.; Donkor, K. K. Determination of thermodynamic $\mathrm{p} K_{\mathrm{a}}$ values of benzimidazole and benzimidazole derivatives by capillary electrophoresis. J. Sep. Sci. 2009, 32, 1087-1095.

25. a) A. H. M. Kirby and A. Neuberger, Biochem. J. 1938, 32, 1146. (b) Lenarcik., B.; Ojczenasz, P. J. Heterocyclic Chem. 2002, 39, 287.

26. Neis, C.; Petry, D.; Demangeon, A.; Morgenstern, B.; Kuppert, D.; Huppert, J.; Stucky, S.; Hegetschweiler, K. Inorg. Chem. 2010, 49, 10092.

27. Siewert, I.; Limberg, C. A. Trispyrazolylborato iron malonato complex as a functional model for the acetylacetone dioxygenase. Angew. Chem. Int. Ed., 2008, 47, 7953-7956.

28. Miao, C. B.; Wang, Y. H.; Xing, M. L.; Lu, X. W.; Sun, X. Q.; Yang, H. T. I2-Catalyzed Direct aHydroxylation of $\beta$-Dicarbonyl Compounds with Atmospheric Oxygen under Photoirradiation. J. Org. Chem. 2013, 78, 11584-11589. 